\title{
Solidification and convection of a ternary solution cooled from the side
}

\author{
By LYNN J. BLOOMFIELD AND HERBERT E. HUPPERT \\ Institute of Theoretical Geophysics, University of Cambridge, Centre for Mathematical Sciences, \\ Wilberforce Road, Cambridge CB3 OWA, UK
}

(Received 5 April 2002 and in revised form 19 March 2003)

Results of an experimental study on the solidification and convection of a ternary solution of $\mathrm{H}_{2} \mathrm{O}-\mathrm{CuSO}_{4}-\mathrm{Na}_{2} \mathrm{SO}_{4}$ when cooled from a vertical side boundary are presented. Cooling and crystallization at a sidewall result in the formation of horizontal gradients of composition and temperature which are restricted to thin boundary layers adjacent to the solid. The dynamics of the buoyancy-induced flows in the compositional and thermal boundary layers is shown to depend critically on the morphology of the growing solid as well as on the density changes in the fluid released on solidification. In a ternary system, the possibility of a density reversal in the residual fluid as a second component solidifies leads to a wide range of possible behaviours. Three broad regimes are identified and the flows which arise in two of these are studied in detail; the behaviour in the third regime can be inferred from these results. When the thermal and compositional boundary layers are both heavy and flow to the base of the tank (regime I), the evolution of the interior fluid is shown to be initially quantitatively similar to that arising from thermal convection only. Slow compositional changes in the interior only later result in a number of doublediffusive effects. When the compositional and thermal buoyancies in the boundary layers are opposed (regimes II and III), a unidirectional downflow, counterflow and upflow are all observed at various stages of the experiment. The onset and duration of these different flows is shown to depend on the ratio of compositional to thermal buoyancies, the relative fluxes in the boundary layers, and the crystal morphology. The effect of surface roughness for the particular ternary system investigated is quantified by measuring its effect on the fluxes in the boundary layers, which allows the modification of existing theories to predict the conditions under which the different boundary layer dynamics arise.

\section{Introduction}

A wide variety of processes, including crystal growth (Hurle 1993), the casting of metals (Kurz \& Fisher 1986) and the freezing of magmas (Chen \& Turner 1980; McBirney 1980; Huppert \& Sparks 1984), involve the solidification of multicomponent systems. In all cases, the preferential solidification of different components of the system over a range of temperatures leads to variations in both the composition and temperature of the fluid. Different combinations of the spatial orientation and stability of these gradients lead to a wide range of possible dynamics. The complexity of these convective flows increases with the number of components present in the solution - hence a ternary solution of three chemically distinct components has more scope for variation in the dynamics than a binary solution. 
The major features of the dynamics of ternary systems can be studied using the simple laboratory system of two salts dissolved in water. A recent investigation into the solidification of a ternary solution was begun by Aitta, Huppert \& Worster (2001). In that study, a ternary solution was cooled from below and and all convection was suppressed because the buoyancy of the fluid released on crystallization always increased. In contrast, the present study focuses on the more complicated, but often more realistic, situation which involves the compositional and thermal convection that arises when a ternary solution is cooled from the side. In a geologically motivated, completely experimental investigation, Turner \& Gustafson (1978) studied the flows caused by the release of compositionally light fluid when a ternary solution solidifies at a central pole. In that case, although the compositional and thermal boundary layers had opposing buoyancies, the compositional decrease in density was sufficient to overcome the thermal increase. In fact, the rising compositional boundary layer dragged the thermal boundary layer to the top of the fluid region, and a number of double-diffusive effects arose. Most subsequent experimental and theoretical studies of solidification from the side have focused on similar flows of cold, but compositionally light, fluid rising adjacent to a smooth surface (Thompson \& Szekely 1987; Leitch 1987, 1989; Huppert 1990; Jarvis \& Huppert 1995). However, none have attempted a systematic study of other possible flows that may arise due to the solidification of an additional component from a ternary solution. The resulting non-monotonic changes in the density of the residual fluid allow additional boundary layer dynamics which do not arise in binary systems. Additionally, very few attempts have been made to quantify the effect of the solid morphology on the compositional and thermal convection, despite the fact that most of the past experiments formed solid surfaces of varying degrees of roughness (Leitch 1987 being one exception). It is the aim of the present study to investigate fully how the buoyancies, fluxes, density changes and morphology combine to produce the variety of flows observed when a ternary system is cooled from the side.

We begin with a brief summary of ternary systems and of the ternary phase diagram in $\S 2$. Three regimes of behaviour, which depend on the density changes of the fluid released on crystallization, are identified. In $\S 3$ the experimental apparatus and techniques are introduced. A theoretical discussion of multi-component boundary layers is then presented in $\S 4$. The dynamics observed in experiments in the first of the behavioral regimes is described in $\S 5$, and the resulting changes to the ambient compositional and temperature are quantified. In $\S 6$ experiments in the second regime are described and the results from these are used to quantify the onset and duration of a number of different stages of the flow. Previous boundary layer theories are then adapted to account for the rough crystal surface that formed in most experiments. The main results and conclusions are then summarised in $\S 7$.

\section{The ternary system}

The ternary system used in this investigation consisted of two solutes (copper sulphate and sodium sulphate) dissolved in water. The main advantages in using this system are that its phase diagram can be easily plotted from previously compiled data (Washburn 1928), it has successfully been used in past solidification experiments (e.g. Turner \& Gustafson 1981; Kerr \& Turner 1982; Kerr \& Tait 1986), and the ternary eutectic temperature of $-3^{\circ} \mathrm{C}$ is easily reached under simple laboratory conditions. The system is complicated slightly by the formation of hydrated crystals of the 
two salts $\left(\mathrm{CuSO}_{4} \cdot 5 \mathrm{H}_{2} \mathrm{O}\right.$ and $\left.\mathrm{Na}_{2} \mathrm{SO}_{4} \cdot 10 \mathrm{H}_{2} \mathrm{O}\right)$ and the formation of a double salt $\left(\mathrm{CuNa}_{2}\left(\mathrm{SO}_{4}\right)_{2} \cdot 2 \mathrm{H}_{2} \mathrm{O}\right)$ at high solute concentrations. However, the effect of a hydrated solid was easily accounted for in the analysis and the salt concentrations were low enough to prevent the formation of the double salt. The only real disadvantage, that the solidification of copper sulphate is known to produce some non-equilibrium effects, was avoided by focusing primarily on the solidification of ice and sodium sulphate.

The solid or liquid phases that are present in thermodynamic equilibrium at any temperature and concentration can be determined from a ternary phase diagram (for a detailed description of ternary phase diagrams see West 1982 or Aitta et al. 2001). The nature of such diagrams is discussed below with reference to the specific system used here (see figure 1). Figure 1 was developed using data compiled from the International Critical Tables (Washburn 1928). The compositions of the three components of the system are measured along triangular axes such that each apex represents $100 \mathrm{wt} \%$ composition of one of the components. The liquidus temperatures - that is, the temperature at which a solid phase will first form as the solution is cooled - are plotted as contours on figure 1. It is possible for either one, two or all three of the components to crystallize at the liquidus temperature, depending on the fluid composition. At the ternary eutectic composition and temperature, ice and both salts (hydrated salts in this system) simultaneously become saturated and solidify, and this eutectic composition is represented by the star on figure 1. The range of compositions and temperatures at which two of the phases crystallize simultaneously are known as the ternary cotectics and are illustrated in figure 1 as the three curves radiating out from the ternary eutectic. In the current system, a fourth cotectic is present as it is possible for a double salt $\left(\mathrm{CuNa}_{2}\left(\mathrm{SO}_{4}\right)_{2}\right)$ to form. However, this additional complication is avoided in the following analysis. The ternary cotectics also separate the phase diagram into three areas, or fields, one for each component (figure $1 b$ ). These fields indicate which component is the first to solidify when the temperature reaches the liquidus value.

As an example of the processes that occur when this ternary solution is cooled, consider a fluid of initial composition X (as represented on figure 1a) and initial temperature $20^{\circ} \mathrm{C}$. Fluid of this composition lies in the $\mathrm{Na}_{2} \mathrm{SO}_{4}$ field (figure $1 b$ ), and consequently this is the first component to solidify. Crystallization of $\mathrm{Na}_{2} \mathrm{SO}_{4} \cdot 10 \mathrm{H}_{2} \mathrm{O}$ begins when the fluid temperature is reduced to the saturation temperature for that composition, which is found from figure $1(a)$ to be $10^{\circ} \mathrm{C}$. The removal of $\mathrm{Na}_{2} \mathrm{SO}_{4} \cdot 10 \mathrm{H}_{2} \mathrm{O}$ leaves the residual fluid depleted in $\mathrm{Na}_{2} \mathrm{SO}_{4}$ and enriched in $\mathrm{H}_{2} \mathrm{O}$ and $\mathrm{CuSO}_{4}$. For crystallization to continue, this residual fluid must be cooled to its liquidus temperature, which decreases from $10^{\circ} \mathrm{C}$ as the composition of the residual fluid continues to change. These compositional changes in the residual fluid can be quantified by following the tie line, which is the straight line connecting the initial fluid composition to the composition of the crystallizing solid. In this system, both solid salts are hydrated and so their compositions lie on the sides of the triangle (for $\mathrm{CuSO}_{4} \cdot 5 \mathrm{H}_{2} \mathrm{O}$ at $63.9 \% \mathrm{CuSO}_{4}, 36.1 \% \mathrm{H}_{2} \mathrm{O}$; for $\mathrm{Na}_{2} \mathrm{SO}_{4} \cdot 10 \mathrm{H}_{2} \mathrm{O}$ at $44.1 \% \mathrm{Na}_{2} \mathrm{SO}_{4}$, $\left.55.9 \% \mathrm{H}_{2} \mathrm{O}\right)$ rather than at the apexes.

Continued crystallization and cooling drives the composition of the residual fluid along the tie line until the point where it reaches the binary cotectic and ice begins to solidify simultaneously with $\mathrm{Na}_{2} \mathrm{SO}_{4} \cdot 10 \mathrm{H}_{2} \mathrm{O}$. The composition of the fluid that is released on crystallization now begins to follow the cotectic (figure $1 b$ ). This continues until the temperature of the fluid reaches the eutectic temperature (in this system $-3^{\circ} \mathrm{C}$ ), at which point $\mathrm{CuSO}_{4} \cdot 10 \mathrm{H}_{2} \mathrm{O}$ also begins to crystallize. Once the 

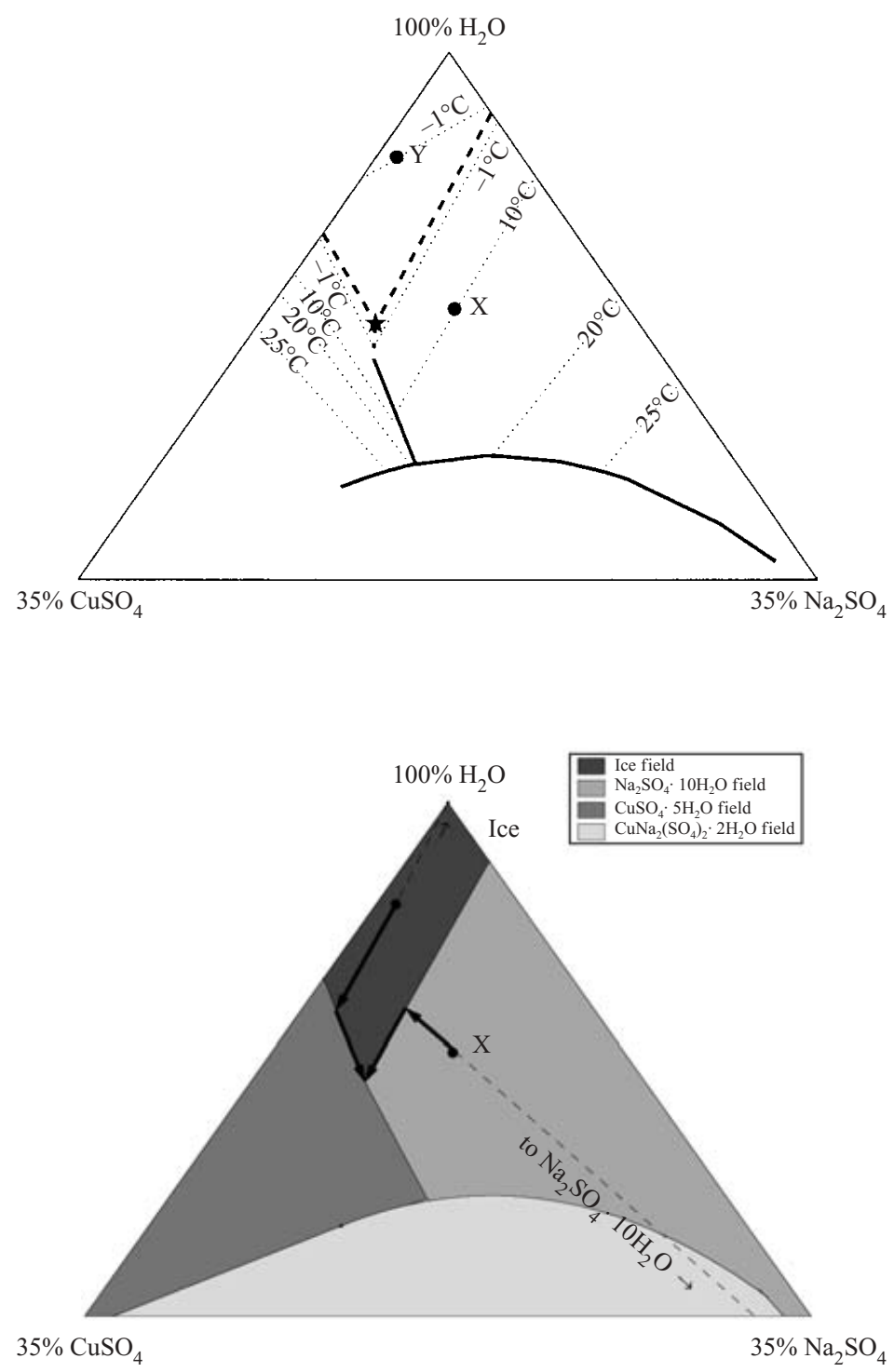

FIgURE 1. The ternary phase diagram for the $\mathrm{H}_{2} \mathrm{O}-\mathrm{CuSO}_{4}-\mathrm{Na}_{2} \mathrm{SO}_{4}$ system. (a) Based on data from the International Critical Tables (Washburn 1928), the solid curves approximate the $\mathrm{CuSO}_{4}-\mathrm{Na}_{2} \mathrm{SO}_{4}$ binary cotectic and the cotectic between the individual salts and the double salt. The bold dashed lines are the best guess for the remaining cotectics. The ternary eutectic is indicated by the $\star$. The light dotted lines are the contours of the liquidus temperature. (b) Illustrative examples of the liquid lines of descent which are followed by fluids of initial compositions $\mathrm{X}$ or $\mathrm{Y}$.

ternary eutectic is reached, further cooling and crystallization releases a residual fluid with a composition that remains at eutectic proportion. Similar processes occur for fluids with compositions originating in the other fields: for example, fluid of initial composition $\mathrm{Y}$ can be cooled to $-1{ }^{\circ} \mathrm{C}$ before the solidification of ice begins. The composition of the salt-enriched residual fluid then follows the tie line and cotectic until the eutectic is reached as one, two and then all three components solidify. The 


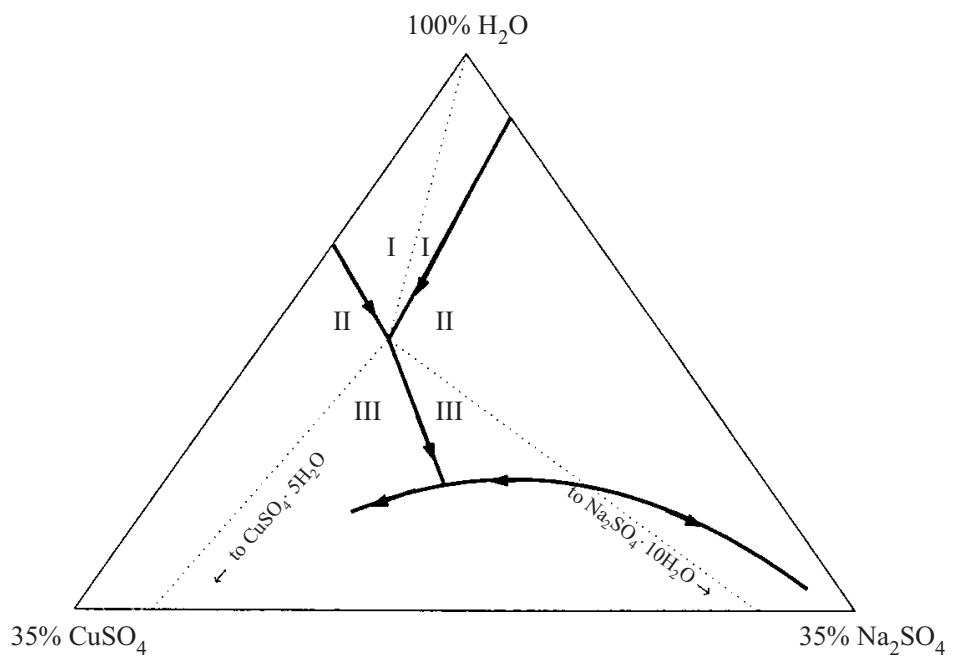

FiguRE 2. Schematic illustration of the ternary phase diagram showing the different regimes of behaviour based on the progressive changes in the density of the residual fluid. The straight solid lines are the cotectics bounding the single salts of the system (and water). The curved solid line is the cotectic bounding the double salt $\mathrm{CuNa}_{2} \mathrm{SO}_{4}$. The arrows indicate the direction of increasing fluid density.

path traced out on the phase diagram by the compositional changes in the residual fluid is referred to as the liquid line of descent.

The fluid dynamics of a ternary system undergoing solidification depends both on the geometry of the system (cooled from below, above or the side) and on the changes in density of the residual fluid as its composition progresses along the liquid line of descent (as in Huppert \& Worster 1985 for binary solutions). For the example given above of fluid $\mathrm{X}$, the density of the residual fluid initially decreases as $\mathrm{Na}_{2} \mathrm{SO}_{4} \cdot 10 \mathrm{H}_{2} \mathrm{O}$ is removed from the solution. However, once the cotectic is reached and ice also solidifies, the density of the residual fluid begins to increase again. For fluid $\mathrm{Y}$, the density of the residual fluid always increases as the continued solidification of ice results in the enrichment of both salts. If the crystallization of the double salt is avoided, then the ternary phase diagram can be separated into three regimes, depending on the density changes along the liquid line of descent (see figure 2). In regime I, the compositional changes along the liquid line of descent always result in an increase in the density of the residual fluid. In regime II, the density of the residual fluid initially decreases, and then increases once the cotectic is reached. In regime III, the density of the fluid always decreases as its composition changes along the liquid line of descent. These regimes, which are illustrated in figure 2, are delineated by a combination of tie lines from the solid compositions to the eutectic, and the binary cotectics. In this investigation, only regimes I and II are considered, because the behaviour in regime III can be easily understood from that observed in regime II. Additional regimes may arise at high solute concentrations beginning in the $\mathrm{CuNa}_{2}\left(\mathrm{SO}_{4}\right)_{2}$ field, when the solidification of the double salt introduces the possibility of further reversals of density in the residual fluid. However, such possibilities remain outside the scope of this investigation. In different ternary systems, it may also be possible to identify a regime in which the the density of the residual fluid initially increases before decreasing after a cotectic is reached. 


\section{Experimental apparatus and techniques}

The experiments were performed in a Perspex tank $50 \times 7.5 \mathrm{~cm}$ in internal crosssection and $30 \mathrm{~cm}$ deep. To fill this tank to capacity, approximately 11 litres of solution was prepared for each experiment using filtered tap water and industrial quality salts. This solution was then filtered again before being added to the tank, which was surrounded at the top, base and all sides by $5 \mathrm{~cm}$ thick expanded polystyrene foam. To cool the solution from the side, a hollow copper plate $50 \mathrm{~cm}$ long, $7 \mathrm{~cm}$ wide and $2 \mathrm{~cm}$ deep was placed inside the tank, flush with one of the narrow endwalls. This copper plate was connected, via a bypass circuit, to a large reservoir of water and ethylene glycol mixture. Before each experiment commenced, this reservoir was precooled to the desired temperature so that when the taps were opened on the bypass circuit, coolant of the correct temperature pumped immediately through the copper plate.

A vertical array of eight thermistors positioned halfway along the length of the tank was used to measure the temperature profile of the fluid at $4-5 \mathrm{~cm}$ intervals. These temperature profiles were logged automatically by computer every $20-30$ s during the initial stages of the experiment, with the time interval increasing to a maximum of approximately $5 \mathrm{~min}$ between profiles after several days. At various stages throughout the experiment, a vertical concentration profile was measured by extracting $2-3 \mathrm{ml}$ samples of fluid from the centre of the tank at $5 \mathrm{~cm}$ intervals. These samples were then analysed using atomic absorption spectrophotometry to obtain concentration measurements of the two salts to within $2 \%$ accuracy. The density of the samples, $\rho$, was not measured directly, but was calculated from the concentration measurements using the approximate relationship

$$
\rho=1+9.7 \times 10^{-3} A+8.6 \times 10^{-3} B+9.8 \times 10^{-5} A^{2}+4.7 \times 10^{-5} B^{2},
$$

in which the constants were obtained from a fit to known data (Washburn 1928) for the relationship between density and concentration of aqueous solutions of $\mathrm{CuSO}_{4}$ $\left(A \mathrm{wt} \%\right.$ ) and $\mathrm{Na}_{2} \mathrm{SO}_{4}(B \mathrm{wt} \%)$. In addition, a comparison between the densities of the samples and measurements of the refractive index, $n$, made on a hand-held refractometer indicated that for the range of densities measured in these experiments, an approximately linear relationship exists of the form

$$
n=1.16+0.17 \rho \text {. }
$$

This relationship permitted the use of refractive index measurements as a real-time estimate of the density changes occurring within the fluid.

\section{Multi-component boundary layers}

The simultaneous cooling and crystallization at a vertical boundary produces horizontal gradients in both temperature and composition. These variations are limited to the region immediately adjacent to the plate, and within these boundary layers the altered density of the fluid results in a net flow. In a ternary system, the different chemical diffusivities of the two solutes results in the formation of two compositional boundary layers in addition to the thermal and viscous boundary layers. The direction in which the boundary layers flow is determined by their buoyancies in these experiments, the compositional boundary layers could either rise or fall, depending on the change in density due to composition, while the cooled thermal boundary layer always falls. The dynamics of two-component boundary layers (one thermal, one compositional) have been investigated in a number of theoretical studies 
(e.g. Gebhart \& Pera 1971; Nilson 1985), all of which are based on the two-dimensional laminar boundary layer equations for steady convection adjacent to a vertical wall. When the simultaneous diffusion of two chemical species is included, these equations become

$$
\begin{aligned}
\frac{\partial w}{\partial z}+\frac{\partial v}{\partial y} & =0 \\
w \frac{\partial w}{\partial z}+v \frac{\partial w}{\partial y} & =v \frac{\partial^{2} w}{\partial y^{2}}+g \alpha\left(T-T_{\infty}\right)+g \beta_{1}\left(C_{1}-C_{1 \infty}\right)+g \beta_{2}\left(C_{2}-C_{2 \infty}\right), \\
w \frac{\partial T}{\partial z}+v \frac{\partial T}{\partial y} & =\kappa \frac{\partial^{2} T}{\partial y^{2}}, \\
w \frac{\partial C_{1}}{\partial z}+v \frac{\partial C_{1}}{\partial y} & =D_{1} \frac{\partial^{2} C_{1}}{\partial y^{2}}, \\
w \frac{\partial C_{2}}{\partial z}+v \frac{\partial C_{2}}{\partial y} & =D_{2} \frac{\partial^{2} C_{2}}{\partial y^{2}},
\end{aligned}
$$

where $v$ and $w$ are the velocity components corresponding to the horizontal direction $y$ and vertical direction $z$, respectively (where $z$ is measured from the origin of the boundary layer - for a cold thermal boundary layer therefore $z$ is measured from the top of the tank), $g$ is the gravitational acceleration, $\alpha$ is the coefficient of thermal expansion, $\beta$ the corresponding coefficients in the density relationship as a function of composition, $T$ is the fluid temperature within the boundary layer, with $T_{\infty}$ the ambient temperature, $C$ is the fluid composition within the boundary layer, with $C_{\infty}$ the ambient composition, $v$ is the viscosity, $\kappa$ is the thermal diffusivity and $D$ is the chemical diffusivity. The subscripts 1 and 2 relate to the two diffusing species. Numerical solutions for these equations under various conditions are discussed later.

Although the experimental conditions will not be constant at the wall and will vary with depth as well as time, equations (4.1) are still useful for obtaining qualitative information about the flow, especially at early times. Some indication of the structure of the boundary layers is even obtainable prior to solving (4.1). The widths of the boundary layers, and the flux of fluid transported within them, depend on their diffusivities. At a temperature of $0{ }^{\circ} \mathrm{C}$, the system has a viscosity of $v \sim$ $2 \times 10^{-2} \mathrm{~cm}^{2} \mathrm{~s}^{-1}$ and a thermal diffusivity of $\kappa \sim 1.4 \times 10^{-3} \mathrm{~cm}^{2} \mathrm{~s}^{-1}$, where these values are averages of the values for aqueous solutions of $\mathrm{CuSO}_{4}$ and $\mathrm{Na}_{2} \mathrm{SO}_{4}$. The chemical diffusivities are $D_{1}=2.4 \times 10^{-6} \mathrm{~cm}^{2} \mathrm{~s}^{-1}$ for $\mathrm{CuSO}_{4}$ and $D_{2}=3.6 \times 10^{-6} \mathrm{~cm}^{2} \mathrm{~s}^{-1}$ for $\mathrm{Na}_{2} \mathrm{SO}_{4}$ (Washburn 1928). These four diffusivities give rise to four different length scales or boundary-layer thicknesses, with the viscous boundary layer the widest and the $\mathrm{CuSO}_{4}$ compositional boundary layer the narrowest. The large differences in the thermal and chemical diffusivities $\left(L e_{1}=\kappa / D_{1}=580, L e_{2}=\kappa / D_{2}=390\right)$ ensures that both the compositional boundary layers remain firmly embedded within the thermal boundary layer. These large Lewis numbers, combined with the ratio of $D_{1} / D_{2} \lesssim 1$ permit the approximation that the dynamics of the two compositional boundary layers are qualitatively similar to that of a single compositional boundary layer. This approximation, which is used to simplify the following analysis to that of a binary system, is further tested in $\S 5.3$.

The flux of fluid in the compositional boundary layer is much less than the corresponding flux in the thermal boundary layer, and the thermal evolution of the ambient fluid therefore proceeds at a much faster rate than the compositional evolution. The stability and strength of the vertical profiles of temperature and 


$\begin{array}{ccccc}\text { Experiment } & T_{i}\left({ }^{\circ} \mathrm{C}\right) & T_{p}\left({ }^{\circ} \mathrm{C}\right) & \% \mathrm{Na}_{2} \mathrm{SO}_{4} & \% \mathrm{CuSO}_{4} \\ \text { IA } & 22 & -11 & 0.6 & * 2.4 \\ \text { IB } & 19.5 & -11 & 1.2 & * 2.7 \\ \text { IC } & 19.5 & -6 & * 1.9 & 1.7 \\ \text { ID } & 20 & -26.5 & * 1.4 & 1.3 \\ \text { IE } & 23 & -20 & 3.9 & * 10.5 \\ \text { IF } & 12 & -18 & 4.0 & * 11.25 \\ \text { IG } & 24 & -20 & 4.1 & * 11.5\end{array}$

TABLE 1. Experimental parameters for the experiments performed in Regime I. The concentration values marked with $\mathrm{a} *$ indicate which salt was the second component to solidify simultaneously with the ice.

composition that are established by these fluxes in the boundary layers depend on the direction of the flow in each layer - and hence significant differences arise between flows in each of the three regimes introduced in $\S 2$.

\section{Regime I}

A series of seven experiments was performed in this regime, five with a $\mathrm{CuSO}_{4}$-rich initial composition (that is, an initial composition for which the tie line intersects the ice- $\mathrm{CuSO}_{4}$ cotectic) and two with a $\mathrm{Na}_{2} \mathrm{SO}_{4}$-rich initial compositions (with a tieline intersecting the ice- $\mathrm{Na}_{2} \mathrm{SO}_{4}$ cotectic). The parameters for these experiments are listed in table 1 , which shows the initial fluid temperature, $T_{i}$, the plate temperature $T_{p}$ and the initial fluid compositions. In all experiments, the plate temperature was maintained well below the eutectic value of $-3^{\circ} \mathrm{C}$.

\subsection{Observations}

In the first regime, the salt-enriched compositional boundary layer and the cold thermal boundary layer are both heavier than the ambient fluid, and consequently both layers flow downwards under buoyancy to the base of the tank. Immediately after an experiment was begun, a thermal boundary layer formed adjacent to the cooling plate, transporting cold fluid towards the base of the tank. Calculated thermal Grasshof numbers, $G r_{T}=g \alpha \Delta T H^{3} / \nu^{2}$ (where $\Delta T$ is the driving temperature difference and $H$ is the depth of the fluid region) of $G r_{T} \sim 10^{9}$ are of the same order as the critical value for the transition to turbulence (Turner 1979). However, visual observations using the shadowgraph technique indicated that this boundary layer remained laminar along the full depth of the plate. The convective flux of increasingly colder fluid to the base established a thermal stratification of increasing depth via a ‘filling box’ process (Baines \& Turner 1969; Turner 1979; Worster \& Leitch 1985). This thermal stratification of the interior proceeded rapidly, taking approximately 1 hour for the entire depth of the ambient fluid to be cooled below its initial temperature.

Several minutes into the experiment, ice began to crystallize and adhere to the cooling plate. The solid grew initially in a wedge at the base, where the ambient fluid temperatures were coldest. After approximately $20 \mathrm{~min}$, the plate was completely covered in a thin layer of ice, with the solid thickness increasing with depth. The onset of solidification and the release of fluid enriched in both salts produced a dense compositional boundary layer, the flux from which established a stable compositional gradient of increasing depth in the interior. The two filling-box processes occurred simultaneously, although the depth of the compositional stratification grew at a 
much slower rate than that of the thermal stratification due to the much smaller compositional flux in the narrower boundary layer.

The growth of stable gradients of temperature and composition in the ambient fluid in turn affected the dynamics of the two-component boundary layer. Fluid from both boundary layers continued to detrain at their heights of neutral buoyancy. Fluid in the inner compositional boundary layer, which was both cold and salty, continued to remain denser than the ambient at all heights, creating a small outflow of cold salty fluid at the base of the tank. The cold fluid in the thermal boundary layer, being mostly of the initial ambient composition, was therefore lighter than the cold, salty fluid within the developing compositional stratification. The thermal boundary layer consequently no longer fell to the base of the tank, but detrained fluid near the top of the compositional stratification. This detrainment at an intermediate height effectively separated the ambient fluid into two layers (Thompson \& Szekely 1987). The upper layer remained compositionally homogeneous, with a thermal evolution that resembled that for pure thermal convection. The lower layer was compositionally stratified but showed little variation in temperature. This separation into two layers was the first evidence of double-diffusive effects in the interior. After several days, further double-diffusive effects became apparent in the formation of additional layers due to the well-known effect of cooling a vertical concentration gradient from the side (Huppert \& Turner 1978, 1980; Huppert, Kerr \& Hallworth 1984). After several days, the entire tank had become compositionally stratified and 2-3 double-diffusive layers had formed.

The crystallization of ice produced a solid of low porosity, which confined the production of salt-enriched fluid to the solid/liquid interface rather than the interstices of a solid mush. Solidification therefore only continued while the interfacial temperature decreased. The rate at which this interfacial temperature fell was limited both by the decreasing effectiveness of heat conduction from the cooling plate through the growing mass of solid ice, and by heat gained through the tank walls. After 34 days most experiments had reached a point of thermal equilibrium and no further solid growth or ambient evolution occurred. The extent to which the fluid composition progressed along the liquid line of descent was therefore quite limited.

\subsection{Experimental results}

Experimental measurements of temperature and compositional profiles in the bulk fluid and a profile of the solid structure are shown in figures 3-8. A typical example (experiment IE) of the evolution of the vertical temperature profile with time is presented in figure 3. This figure clearly shows the formation of a stable, almost linear temperature gradient at early times (figure $3 a, b$ ), which is eventually disrupted by the growth of the compositional stratification. The resulting intermediate detrainment of the thermal boundary layer is observed as a cold outflow at depths which increase in time (figure $3 c, d$ ).

Measurements of the changing ambient compositional profile from one of the experiments (ID) are shown in figure 4. Figures $4(a)$ and $4(b)$ show the enrichment in both salts at the base of the tank as the compositional stratification is established, and further illustrate the slow variations in ambient concentration. The ratio $\mathrm{Na} / \mathrm{Cu}$ in the residual fluid remains constant (see figure $4 c$ ) for fluid on the tie line, and in this experiment, thermal equilibrium was reached before the simultaneous crystallization of $\mathrm{Na}_{2} \mathrm{SO}_{4}$ could begin to decrease the ratio of $\mathrm{Na} / \mathrm{Cu}$. The compositional measurements from various depths throughout experiments ID and IE are plotted on a ternary 

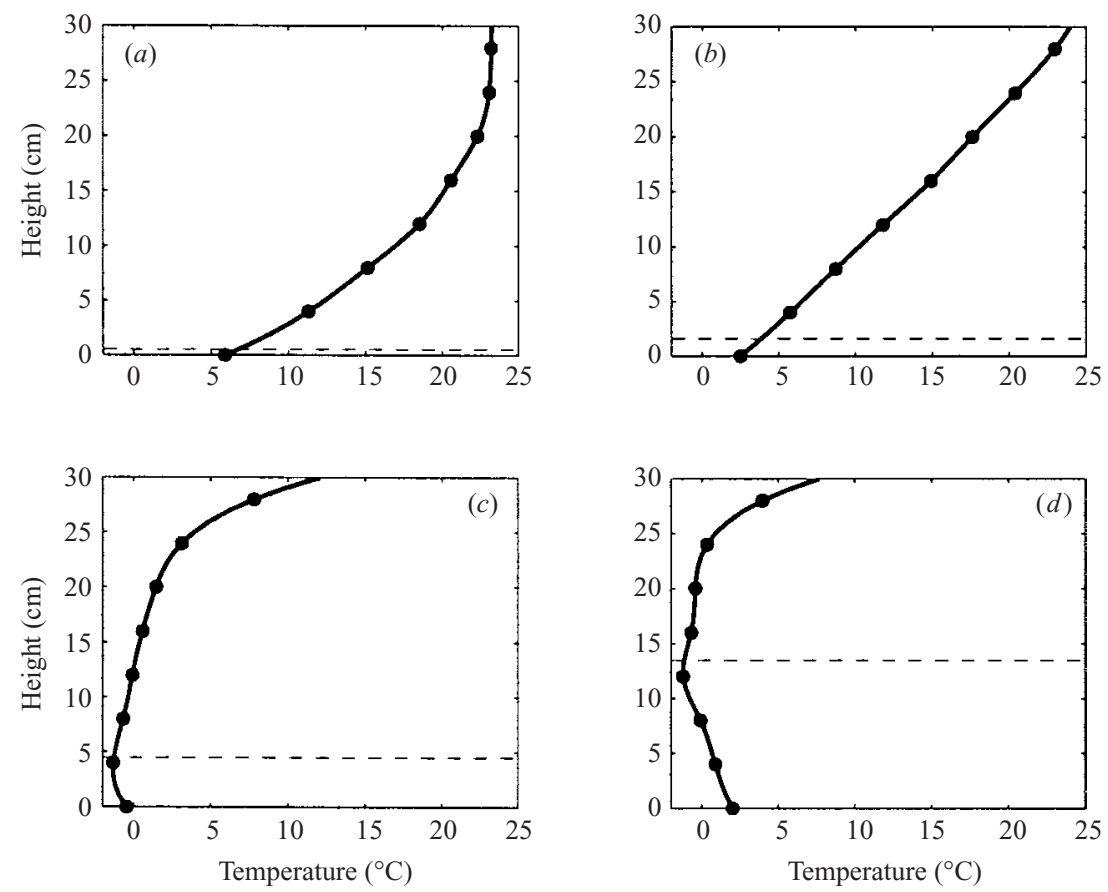

FIGURE 3. Vertical temperature profiles measured after $(a) 1 / 2$ hour, $(b) 1$ hour, $(c) 5$ hours and $(d) 15$ hours. The dashed lines show the measured position of the top of the compositional stratification obtained from the compositional profile.
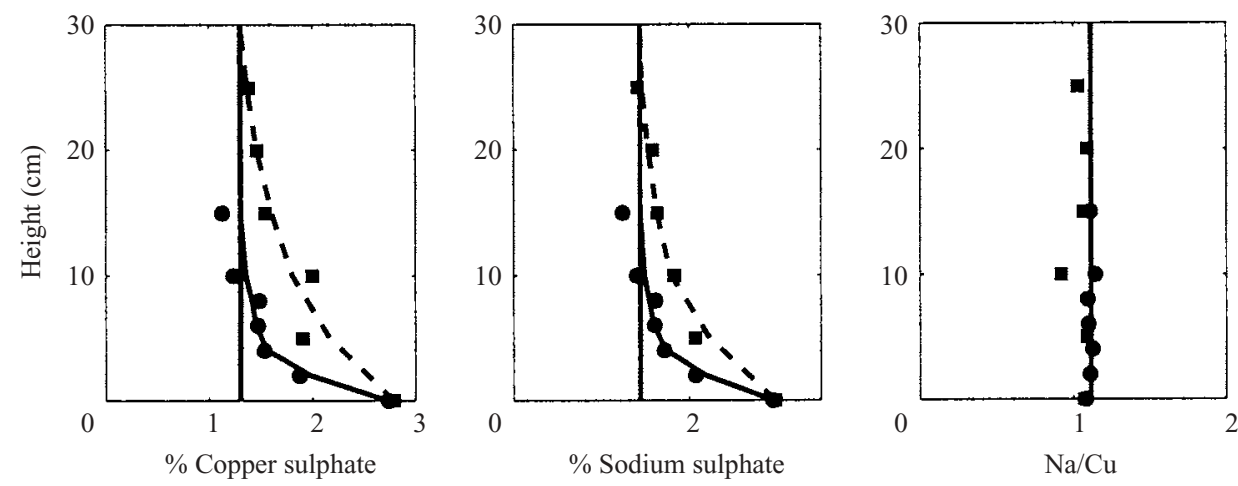

Figure 4. Typical compositional changes for fluid in regime I after 17 hours $(\bullet)$ and 41 hours (ם). Profiles of $(a)$ copper sulfate and $(b)$ sodium sulfate clearly show the slow development of the compositional stratification. $(c)$ The ratio $\mathrm{Na} / \mathrm{Cu}$ remains constant, as it should for fluid on the tie line.

phase diagram in figure 5, showing clearly the evolution along the liquid line of descent.

In figure 6, data from five of the experiments (IA-IE) are used to plot the depth at which the thermal boundary layer detrains, $\zeta_{o}=\left(H-z_{o}\right) / H$ (which is measured as the position of the thermistor measuring the coldest fluid in the thermal gradient) against the position of the top of the compositional stratification, $\zeta_{C}=\left(H-z_{C}\right) / H$, which was measured as the depth where the compositional measurements deviated 


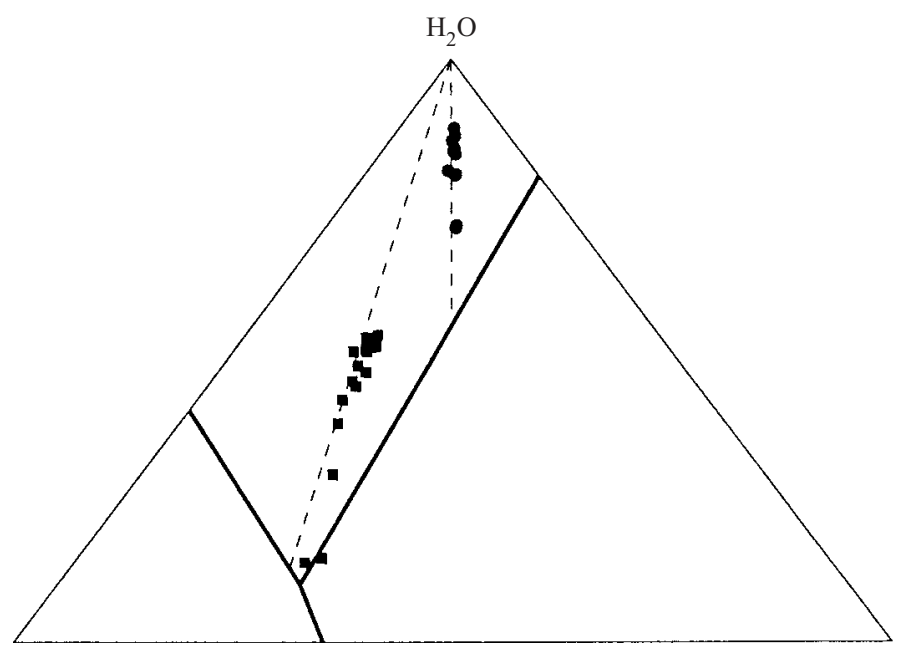

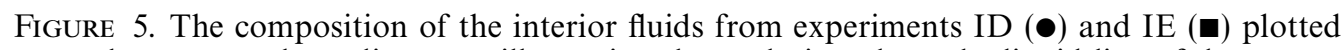
on the ternary phase diagrams, illustrating the evolution along the liquid line of descent.

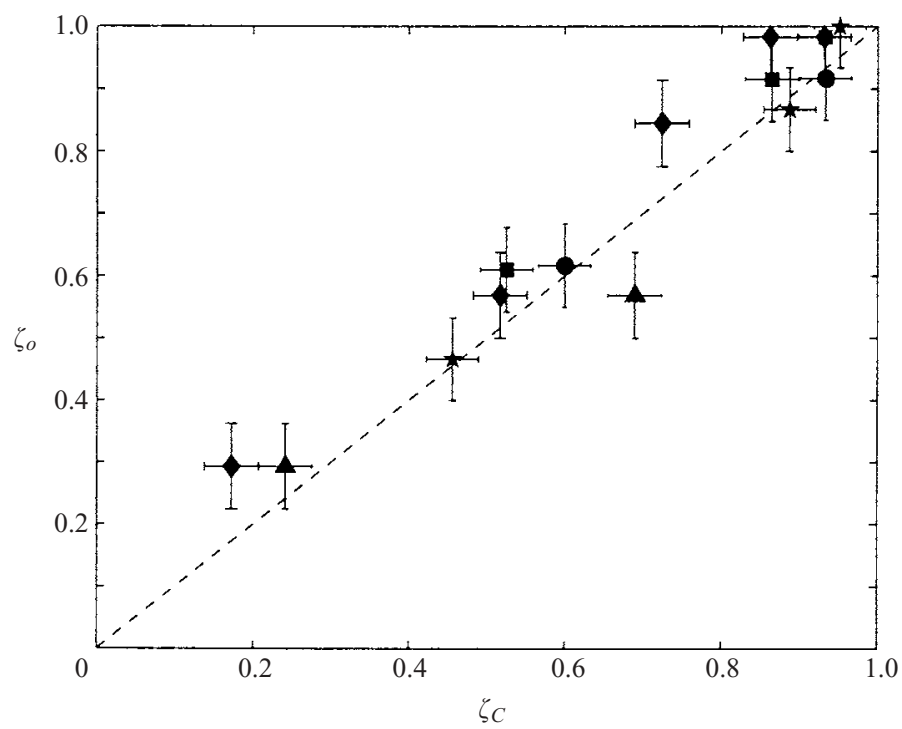

FiguRE 6. Dimensionless position of the coldest fluid in the tank, corresponding to the position of the cold thermal outflow, plotted against the dimensionless position of the top of the compositional stratification at various times throughout each experiment. The different symbols represent experiments IA $(\bullet)$, IB $(\bullet)$, IC $(\bullet)$, ID $(\boldsymbol{\Delta})$ and IE $(\star)$.

by $1 \%$ from the initial composition. The relationship between these depths is close to $1: 1$, confirming that the cold thermal boundary layer detrains at or near the top of the compositional stratification.

In one experiment, the growth of the solid was monitored closely. Figure 7 shows that initially the solid ice formed in a wedge at the base of the tank where the cold fluid transported in the thermal boundary layer had already begun to accumulate. The fastest growth of the solid always coincided with the depth of the lowest ambient fluid temperature, and the solid growth was limited in the upper regions of the 


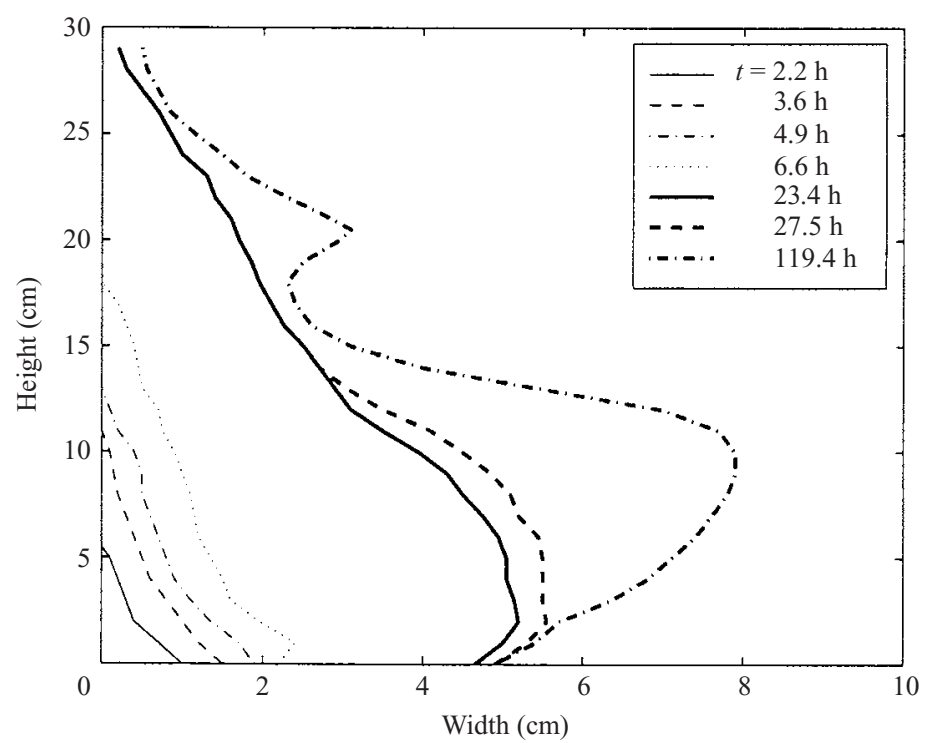

FIgURE 7. Profiles of the solid ice at various times throughout experiment IA. The faster growth at the positions of coldest ambient fluid result in the scalloped profile at later times.

tank where heat gains maintained warmer ambient temperatures. These differences in growth rates eventually led to the solid developing a scalloped profile, due to the faster growth occurring at the bases of the double-diffusive layers (Turner \& Gustafson 1981). Changes in the growth rate of the solid also resulted in variations in the composition and structure of the solid ice. Close to the plate, the solid was an opaque, dark blue colour, due to the subsequent solidification of $\mathrm{CuSO}_{4} \cdot 5 \mathrm{H}_{2} \mathrm{O}$ (and $\mathrm{Na}_{2} \mathrm{SO}_{4} \cdot 10 \mathrm{H}_{2} \mathrm{O}$ ) from the small amounts of interstitial fluid that was trapped initially in the porous ice. The blue colouration was observed to decrease both with increasing distance from the plate and with height. The upper few centimetres of the solid (which remained less than $1 \mathrm{~cm}$ thick), as well as the outer $2 \mathrm{~cm}$ of the solid were generally translucent, indicating the presence of pure ice with little or no trapped interstitial fluid. In an attempt to determine if these observations can be correlated to a changing porosity, the solid from one experiment (IA) was removed after the completion of the experiment and core samples were taken from various locations. These samples were then melted and the concentrations of the salts measured by atomic absorption spectrophotometry. In this experiment, the average ambient fluid composition did not vary significantly from its initial value, and hence the measured concentrations of $\mathrm{CuSO}_{4}$ or $\mathrm{Na}_{2} \mathrm{SO}_{4}$ were used to provide an estimate of the variations in the solid porosity (figure 8 ). This calculation was achieved by assuming that the solid formed was pure ice and that any $\mathrm{CuSO}_{4}$ or $\mathrm{Na}_{2} \mathrm{SO}_{4}$ in the melt was due to fluid that must have been trapped within the pores of the solid.

Due to the limiting effects of heat gains into the system, later experiments were necessarily started with a composition much closer to the eutectic in order to reach and progress along the cotectic. Three experiments were performed with initial salt concentrations close to the ice- $\mathrm{CuSO}_{4}$ cotectic (IE-IG). These experiments were affected at later times by the delayed formation of the $\mathrm{CuSO}_{4} \cdot 5 \mathrm{H}_{2} \mathrm{O}$ crystals, which is a well-known non-equilibrium effect — the fluid must be significantly supercooled before the salt will crystallize. Initially, ice formed against the plate as before, forming 


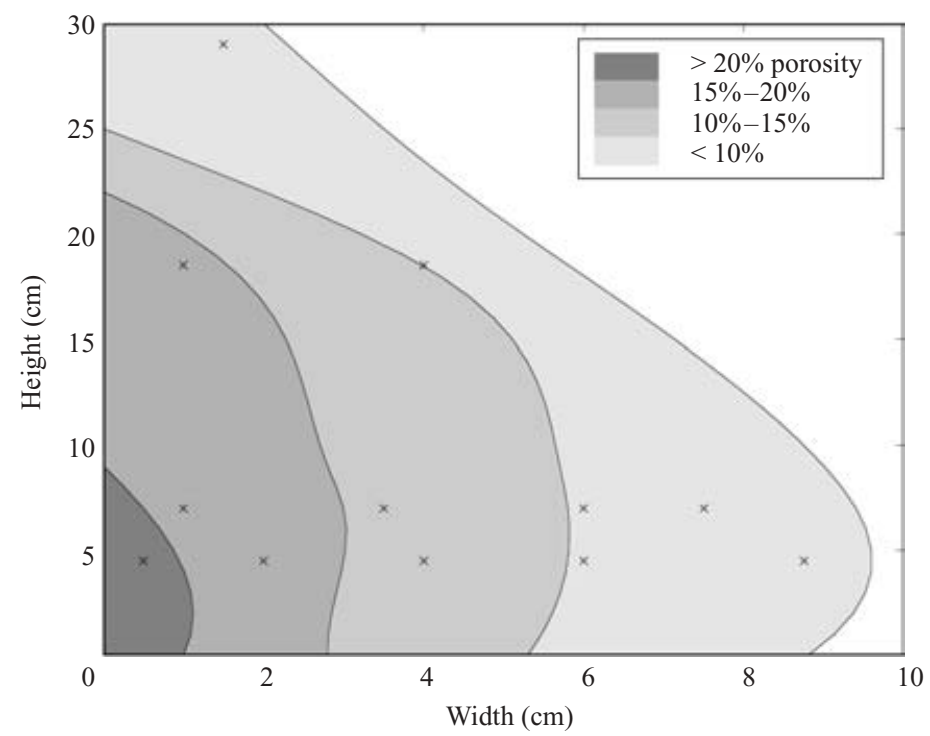

FiguRE 8. Estimates of the solid porosity based on measurements of the salt content in the solid ice (experiment IE). The regions are approximated from the 12 measurements taken at the positions marked with crosses.

a wedge shape which later developed a scalloped profile. After several days, copper sulphate began to crystallize simultaneously with the ice, but instead of solidifying on the solid/liquid interface, the blocky $\mathrm{CuSO}_{4} \cdot 5 \mathrm{H}_{2} \mathrm{O}$ crystals formed a thin layer on the base of the tank (the supercooled fluid has sufficient time to form a layer over the base before crystallization occurs). With the further solidification of ice on the vertical solid boundary, the layer of $\mathrm{CuSO}_{4}$ crystals became embedded in the lower few centimetres of the ice block. Eventually, the base of the tank was completely covered in a $5 \mathrm{~mm}$ thick layer of $\mathrm{CuSO}_{4}$ crystals around which some white $\mathrm{Na}_{2} \mathrm{SO}_{4} \cdot 10 \mathrm{H}_{2} \mathrm{O}$ crystals were also starting to grow. From visual observations alone, it could not be determined whether any additional $\mathrm{Na}_{2} \mathrm{SO}_{4}$ crystals were forming and adhering to the vertical solid/liquid interface. The fluid released on crystallization of pure $\mathrm{CuSO}_{4}$ along the base of the tank would have been lighter than the ambient, but compositional measurements at this stage were too infrequent to see any indication of the expected compositional convection.

\subsection{Theoretical predictions}

In a study of thermal boundary layers without solidification, Worster \& Leitch (1985) used solutions of the boundary layer equations to quantify the growth of the ambient stratification during the filling-box process. A similar approach is used here to quantify how the presence of compositional boundary layers affect the development of both compositional and thermal gradients. Initially, the equations are solved for the two distinct chemical species to confirm the validity of the approximation of a single compositional boundary layer. Equations (4.1) are solved following the analysis of Gebhart \& Pera (1971), with a dimensionless temperature defined as $\theta=\left(T-T_{\infty}\right) /\left(T_{s}-T_{\infty}\right)$ and dimensionless composition as $\phi=\left(C-C_{\infty}\right) /\left(C_{s}-C_{\infty}\right)$, where $C$ and $T$ are the compositions and temperatures throughout the boundary layers, $C_{s}$ and $T_{s}$ are the compositions and temperatures at the solid/liquid interface and $C_{\infty}$ and $T_{\infty}$ are the compositions and temperatures in the bulk fluid. The stream 
function is defined as $\psi=v c(z) f(\eta)$ with the similarity variable $\eta=b(z) y$. Neglecting any ambient stratification, values of the functions are written as

$$
b(z)=G / 4 z, \quad c(z)=G, \quad G=4\left(\frac{z}{H}\right)^{3 / 4}\left(\frac{G r_{T}+G r_{C 1}+G r_{C 2}}{4}\right)^{1 / 4},
$$

where $G r_{T}=g \alpha \Delta T H^{3} / \nu^{2}$ is the thermal Grasshof number and $G r_{C 1,2}=$ $g(\beta \Delta C)_{1,2} H^{3} / \nu^{2}$ are the compositional Grasshof numbers for the two chemical species. The introduction of (5.1) in (4.1) transforms the boundary layer equations into the ordinary differential equations (where differentiation is with respect to $\eta$ )

$$
\begin{gathered}
f^{\prime \prime \prime}+3 f f^{\prime \prime}-2 f^{\prime 2}+\frac{\theta+\Gamma_{1} \phi_{1}+\Gamma_{2} \phi_{2}}{1+\Gamma_{1}+\Gamma_{2}}=0, \\
\theta^{\prime \prime}+3 \operatorname{Pr} f \theta^{\prime}=0, \\
\phi_{1}^{\prime \prime}+3 S c_{1} f \phi_{1}^{\prime}=0, \\
\phi_{2}^{\prime \prime}+3 S c_{2} f \phi_{2}^{\prime}=0,
\end{gathered}
$$

where $\operatorname{Pr}=v / \kappa$ is the Prandtl number, $S c_{1,2}=v / D_{1,2}$ the Schmidt numbers, and $\Gamma_{1,2}=(\beta \Delta C)_{1,2} / \alpha \Delta T$ are buoyancy ratios. The boundary conditions are

$$
\begin{gathered}
f^{\prime}(0)=f(0)=f^{\prime \prime}(\infty)=0, \\
\theta(0)=\phi_{1,2}(0)=1, \\
\theta(\infty)=\phi_{1,2}(\infty)=0 .
\end{gathered}
$$

In order to satisfy the boundary conditions at large $\eta$, a shooting method is used in which the initial guesses for $f^{\prime \prime}(0), \theta^{\prime}(0)$ and $\phi_{1,2}^{\prime}(0)$ are refined after each iteration using a Newton-Raphson method (Press et al. 1992).

The solution of (5.2) for $P r=14, S c_{1}=5000, S c_{2}=3300$, and $\Gamma_{1}=\Gamma_{2}=1$ is shown in figure 9. The choice of values for $\Gamma_{1}$ and $\Gamma_{2}$ are somewhat arbitrary, although experimental measurements indicate that they are both of the order unity. Figure $9(a)$ illustrates the vastly different length scales for the compositional, thermal and viscous boundary layers, and figure $9(b)$ clearly shows the close coincidence of the two compositional boundary layers. Any effect of the different chemical diffusivities is therefore assumed to be small, and indeed no such effect was observed experimentally. A solution of the equations for only one diffusing species $\left(\Gamma=\Gamma_{1}+\Gamma_{2}\right.$ and $\left.S c=\left(S c_{1}+S c_{2}\right) / 2\right)$ yields virtually identical results for the velocity and temperature profiles, and averages the compositional profile. For simplicity, this solution for only one compositional boundary layer is used in the following analysis.

To determine the rate at which the regions of compositional and thermal stratification grow, an expression for the conservation of mass flux at the depth $z_{o}$ is used (Worster \& Leitch 1985)

$$
L \frac{\mathrm{d} z_{o}}{\mathrm{~d} t}=-\psi\left(z_{o}\right)
$$

where $L$ is the length of the tank. In this and the subsequent analysis, horizontal variations within the bulk fluid are neglected, allowing $\psi$ to be considered a function of depth only.

The choice of which level in the respective gradients to focus on is arbitrary; in this analysis the depth at which $\theta_{i}=0.3$ is chosen for the thermal filling-box process and the depth at which $\phi_{i}=0.01$ is chosen for the compositional filling-box process. To integrate equation (5.4), values for $\psi\left(\theta_{i}\right)$ and $\psi\left(\phi_{i}\right)$, where $\psi=v G f$, are found from 

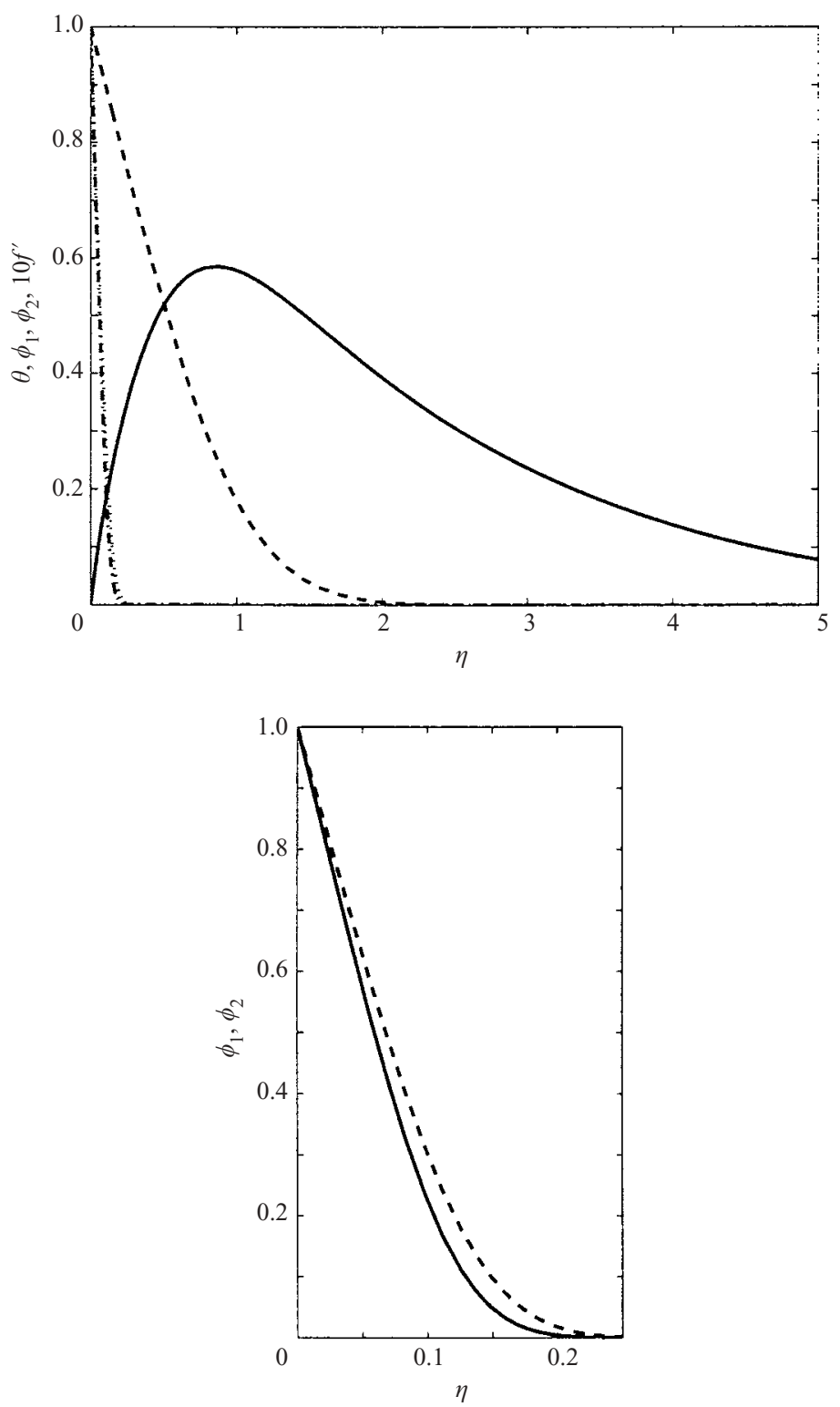

FiguRE 9. The results of the solution of the boundary layer equations for two diffusing chemical species. (a) The non-dimensionalized velocity (-), temperature (- -) and compositions $(\cdots$ and $\cdots)$ as a function of the similarity variable $\eta .(b)$ A more detailed view of the small difference between the profiles of the two chemical species.

the numerical solution for $f(\eta)$. Integration of (5.4) gives

$$
\begin{aligned}
& \zeta_{T}=\left(1-\frac{1}{\sqrt{2}} \tau(1+\Gamma)^{1 / 4} f\left(\theta_{i}\right)\right)^{4}, \\
& \zeta_{C}=\left(1-\frac{1}{\sqrt{2}} \tau(1+\Gamma)^{1 / 4} f\left(\phi_{i}\right)\right)^{4},
\end{aligned}
$$




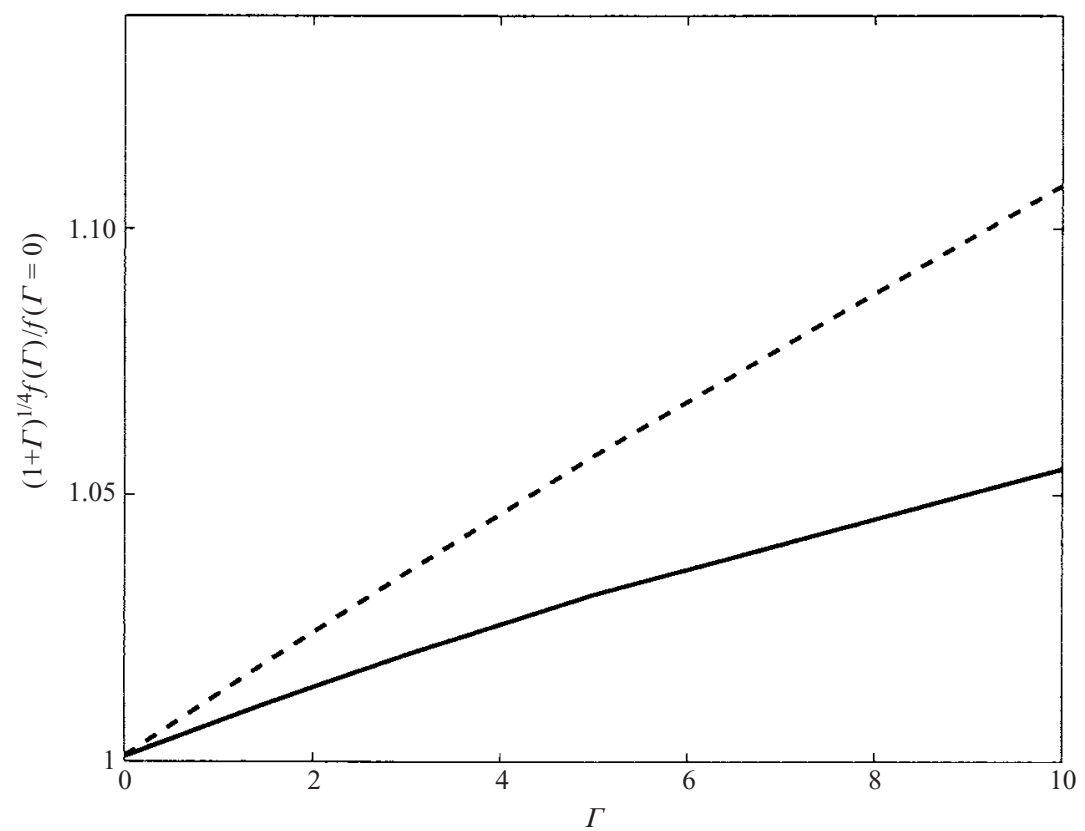

Figure 10. The effect of changing $\Gamma$ on the fluxes in the thermal boundary layer (solid line) and compositional boundary layer (dashed line). The results are normalized by the calculated fluxes for $\Gamma=0$.

where $\zeta_{T}=\left(H-z_{T}\right) / H$ is the dimensionless height of the $\theta_{i}$ isotherm, $\zeta_{C}=$ $\left(H-z_{C}\right) / H$ is the dimensionless position of the $\phi_{i}$ isopycnal and $\tau=v G R_{T}^{1 / 4} t /(L H)$ is the dimensionless time.

Before these equations can be used, it must be noted that in solidification experiments, both $G r_{T}$ and $G r_{C}$ (and hence $\Gamma$ ) vary with time as both the ambient conditions and the properties at the solid/liquid interface evolve. At $t=0$, the temperature difference driving the thermal convection is $\Delta T=T_{\infty}-T_{p}$, and as solidification has yet to begin, $\Gamma=0$. At the onset of solidification, the temperature at the solid/liquid interface is equal to the saturation temperature of the initial fluid composition, $T_{s}$ (which can be calculated from the ternary phase diagram), while the average ambient temperature has decreased slightly from its initial value. A fixed maximum value of $G r_{T}$ based on the difference between the initial fluid temperature and $T_{s}(t=0)$ is used in the subsequent analysis and gives an indication of the maximum possible temperature effect.

In order to determine the theoretical effect of $\Gamma$ on the filling-box process, equations (5.2) were solved for a range of $\Gamma$, and the resulting values of $(1+\Gamma)^{1 / 4} f$ for $f\left(\theta_{i}\right)$ and $f\left(\phi_{i}\right)$ normalized by the value at $\Gamma=0$, are plotted against $\Gamma$ in figure 10 . These calculations were limited to the range $0<\Gamma<10$, because experimental measurements of the average ambient fluid properties compared with possible variations in the conditions at the solid/liquid interface indicate that variations outside this range of $\Gamma$ are unlikely. From figure 10, it is clear that the effect of a compositional boundary layer on the thermal filling-box process is almost negligible: it causes the rise of the isotherm under consideration to increase by around $5 \%$. The rate of compositional stratification shows greater variation from its value at $\Gamma=$ 0 . The results for the compositional flux at $\Gamma=0$ apply when horizontal variations 


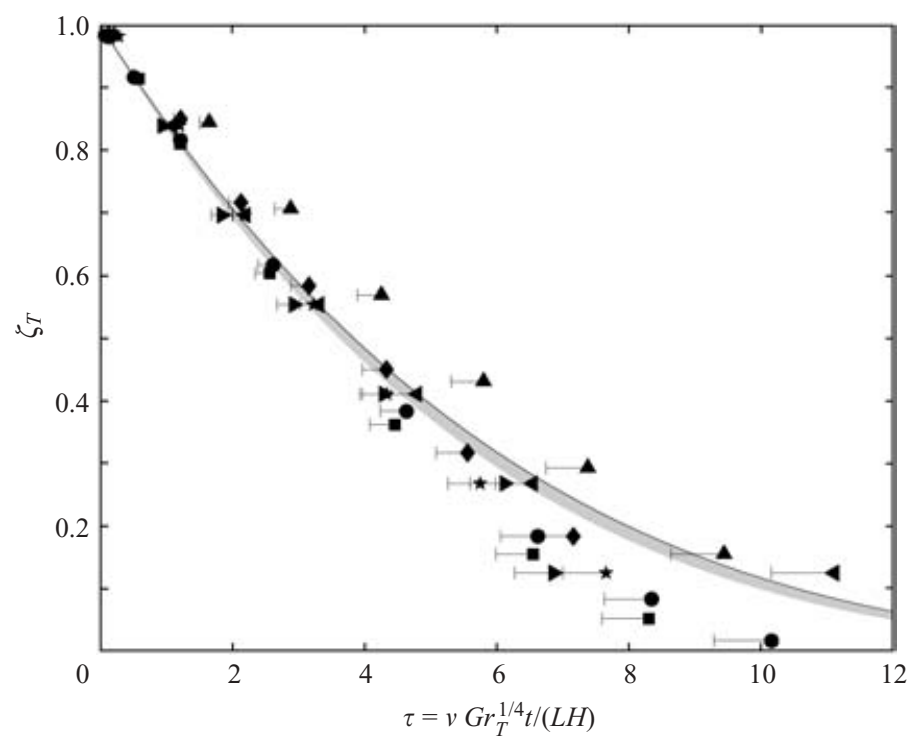

FIGURE 11. The dimensionless height of the $\theta=0.3$ isotherm plotted against dimensionless time, $\tau$, along with the theoretical predictions for $\Gamma=0$ (solid line) and $0<\Gamma<10$ (shaded

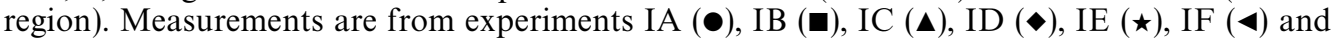
IG ( ).

in composition are still present, but do not add to the net buoyancy of the flow. Then, the flux of this fluid dragged within the viscous boundary layer still results in a compositional stratification in the interior.

In figure 11 the thermistor measurements from seven experiments are used to plot the $\zeta_{T}$ against the dimensionless time, $\tau$. Experimental estimates indicate a drop of up to $30 \%$ in $G r_{T}$ during the period covered in figure 11, and this would produce the variations in $\tau$ that are indicated by the error bars. Also plotted is the theoretical result for a pure thermal boundary layer, which shows good agreement with the experimental results. The shaded region illustrates the possible variations in the growth of the stratification due to an additional compositional boundary layer. Under these experimental conditions, it is therefore seen that the presence of a compositional boundary layer slightly increases the flux in the thermal boundary layer, but this effect is not large. The good agreement between the experimental and theoretical results also confirms that the boundary layer is laminar, as expected.

Figure 12 shows similar results for the compositional stratification along with the theoretical results for $0<\Gamma<10$. In this case, the experiments show a slower stratification than predicted theoretically, even when the effects of varying $\Gamma$ are included. This could be due to the further decreases in $G r_{T}$ with time that were neglected in this analysis, but become significant at the large time scales on which compositional stratification grows. Experimental measurements suggest that the driving temperature difference $\Delta T$ decreases by up to $80 \%$ after several days, resulting in large variations in the experimental data, as indicated by the error bars which now approach the theoretical curve.

In regime I, the crystallization of ice forms a smooth, closely packed solid and hence no additional effects due to variations in the crystal morphology are observed. In contrast, the behaviour observed in regime II shows a critical dependence on the roughness of the solid surface. 


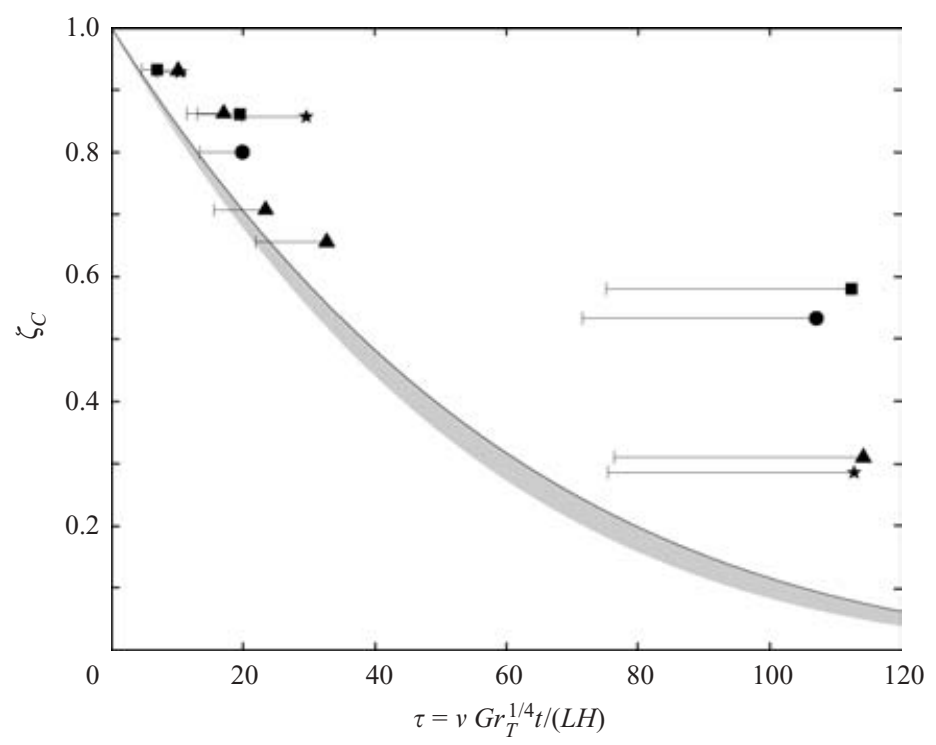

FIGURE 12. The dimensionless height of the $\phi=0.01$ isopycnal plotted against dimensionless time, $\tau$, with the results calculated from the boundary layer equations for $0<\Gamma<10$ shown as the shaded area.

$\begin{array}{ccccccc}\text { Experiment } & T_{i}\left({ }^{\circ} \mathrm{C}\right) & T_{p}\left({ }^{\circ} \mathrm{C}\right) & \% \mathrm{Na}_{2} \mathrm{SO}_{4} & \% \mathrm{CuSO}_{4} & H & L \\ \text { IIA } & 23 & -26 & 5.22 & 2.62 & 29 & 48 \\ \text { IIB } & 17.5 & -24 & 5.36 & 2.68 & 30 & 48 \\ \text { IIC } & 15 & -21 & 5.94 & 2.01 & 25 & 24 \\ \text { IID } & 28 & -15 & 7.02 & 2.05 & 29.5 & 48 \\ \text { IIE } & 20 & -16.7 & 8.98 & 2.32 & 29.5 & 48 \\ \text { IIF } & 20 & -10 & 10.80 & 2.38 & 29 & 48 \\ \text { IIG } & 20 & -5 & 11.9 & 2.4 & 29 & 48 \\ \text { IIH } & 20 & -15 & 11.9 & 2.4 & 29 & 48\end{array}$

TABLE 2. Parameters for the experiments in regime II, listed in order of observed increasing surface roughness.

\section{Regime II}

The parameters from the eight experiments that were performed in this regime are listed in table 2, which shows the initial fluid temperature, plate temperature, initial compositions and tank size (height, $H$ and length, $L$ ) listed in order of increasing apparent surface roughness. As in regime I, the plate temperature was always maintained well below the eutectic temperature of $-3^{\circ} \mathrm{C}$.

\subsection{Observations}

In the second of the regimes introduced in $\S 2$, the density of the residual fluid initially decreases as the fluid becomes depleted in the single crystallizing salt. However, when the binary cotectic is reached and ice begins to crystallize simultaneously with the first salt, the density of the residual fluid increases. This reversal of density due to compositional changes further increases the range of possible behaviour over that previously observed for flows in this regime (Turner \& Gustafson 1981). 
When the fluid released on crystallization is less dense than the ambient fluid, the magnitude and direction of the flow in the boundary layers are strongly affected by the competition between the cold but compositionally light inner layer and the cold heavy outer thermal layer. Additionally, the dynamics of the boundary layer flows are further complicated by the roughness of the solid surface, which varied in the experiments reported here from being completely smooth to consisting of a wall of protruding dendrites $0.5-2 \mathrm{~cm}$ in length. When the vertical surface is smooth and impervious, the boundary layer equations can be solved to obtain theoretical predictions for the magnitude and direction of the fluxes in both boundary layers under a range of conditions (Nilson \& Baer 1982). The additional effect of surface roughness has previously only been investigated quantitatively (Leitch 1987). In the present investigation, a further attempt is made to quantify the effect of surface roughness, particularly in relation to the theoretical predictions of Nilson \& Baer (1982).

All of the experiments in regime II began in the sodium sulphate field with the tie line running to the sodium sulphate-ice cotectic (see figure 2). Immediately after an experiment commenced, a cold thermal boundary layer flowed to the base of the tank. The subsequent behaviour then depended critically on the morphology of the growing solid. Two sets of experiments were performed, exhibiting qualitatively differing behaviour - the first produced a closely packed solid with a smooth surface, and the second a more loosely packed solid of higher porosity and rougher surface.

The first set of experiments (IIA-IIC, see table 2) was performed with initial compositions close to the binary cotectic. In these experiments, the $\mathrm{Na}_{2} \mathrm{SO}_{4}$ crystals formed a closely packed solid with low porosity and a relatively smooth surface (see figure 13a). The onset of crystallization after several minutes resulted in the release of compositionally light fluid in the form of a narrow boundary layer. However, the small compositional difference between the light residual fluid and the ambient was not sufficient to overcome the negative thermal buoyancy due to the residual fluid also being colder than the ambient. Consequently, the compositional boundary layer flowed with the thermal boundary layer to the base of the tank. This unidirectional downflow continued for approximately 6 hours, during which time the thermal buoyancy of the compositional boundary layer decreased (as the ambient fluid temperature approached that of the crystal surface) while the compositional differences between the residual fluid and the ambient increased. While these changes reduced the strength of the downward driving buoyancy, they were not sufficient to alter the dynamics of the boundary layers. Unidirectional downflow therefore continued until some long $\mathrm{Na}_{2} \mathrm{SO}_{4} \cdot 10 \mathrm{H}_{2} \mathrm{O}$ crystals began to protrude approximately $1 \mathrm{~mm}$ through the smooth crystal face, at which point the onset of counterflow in the boundary layers was observed. This counterflow arose due to a combination of the decreased downward driving buoyancy and the rough surface increasing the surface area available for further crystallization and hence resulting in a greater flux of compositionally light residual fluid (Leitch 1989). The inner, compositional boundary layer continued to rise adjacent to the solid, winding around the protruding crystals until it reached the top of the fluid. The outer thermal boundary layer appeared to remain laminar as it fell to the base. During this period of counterflow in the boundary layers, there were two competing filling-box processes occurring, with a large flux of cold fluid arriving at the base to maintain a stable thermal gradient there, while a much smaller flux of cold, depleted fluid arrived at the top, establishing a stable compositional gradient and a weak, unstable thermal gradient. This unstable thermal gradient rapidly diffused due to heat gains through the insulation surrounding 
(a)

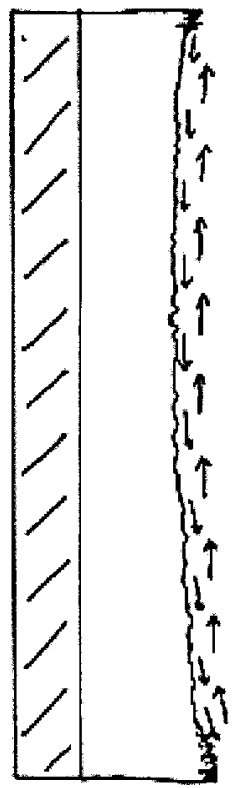

(b)

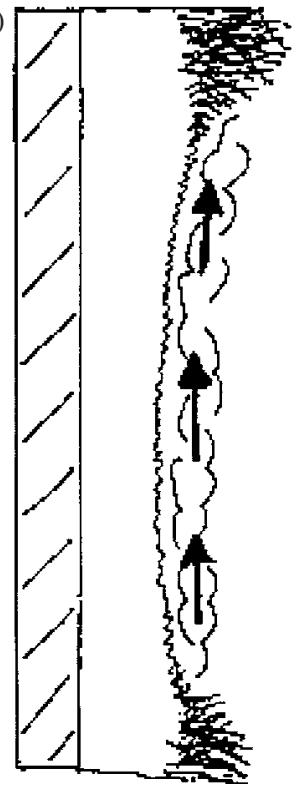

FIGURE 13. Illustrative line drawing of the differences in surface roughness observed in experiments in the second regime, and their effect on the dynamics of the boundary layers. (a) A flat solid surface and the resulting counterflow in the boundary layers, $(b)$ a rough solid surface and the resulting mixed turbulent flow.

the tank, with the result that the thermal gradient at the top of the tank tended to stabilize. In this example, the counterflow in the boundary layers continued until the binary cotectic was reached. The simultaneous crystallization of ice then resulted in an increase in the compositional density of the residual fluid. The net density of the compositional boundary layer (due to the combined effects of composition and temperature) therefore became equal to that at various intermediate heights in the previously established ambient compositional gradient. However, the continued downflow in the outer thermal boundary layer prevented any intermediate detrainment of the inner compositional boundary layer. Instead, the compositional boundary layer was dragged by the thermal boundary layer past its height of neutral buoyancy to the base of the tank, where on detrainment some upward mixing was observed visually. This continued until the net density of the compositional boundary layer increased beyond the maximum in the ambient, after which the downward driving buoyancies in both boundary layers reproduced the flow described for regime I.

The second set of experiments (IID-IIH, see table 2) had initial compositions further from the cotectic and the fluid was much closer to being saturated at its initial temperature. In these experiments, solidification began almost immediately, with the formation of a loose aggregate of long $(0.25-2 \mathrm{~cm})$, thin $(<2 \mathrm{~mm}) \mathrm{Na}_{2} \mathrm{SO}_{4} \cdot 10 \mathrm{H}_{2} \mathrm{O}$ crystals. Fluid trapped initially within this matrix froze rapidly, and convection was limited to the rough solid/liquid interface. The compositionally light residual fluid rose from the crystals as a series of turbulent plumes, rather than as a laminar boundary layer (figure 13b). Competition between this vigorously rising fluid and the falling thermal boundary layer continued for approximately $10 \mathrm{~min}$. By this stage, the length of the crystals was comparable to the width of the thermal boundary layer and the vigorous compositional plumes mixed with the thermal boundary layer to create 
a single mixed flow of cold but light fluid which rose turbulently to the top of the fluid region. The large flux of cold fluid arriving at the top of the tank established an unstable thermal gradient which opposed the stable compositional gradient, resulting in the formation of double-diffusive layers. These layers, which were clearly observed on the shadowgraph, were each several centimetres deep and extended throughout the entire depth of the fluid. The surface of the solid remained rough, maintaining a turbulent unidirectional upflow until the binary cotectic was reached. After the reversal in density of the residual fluid, the mixed upflow detrained at its intermediate height of neutral buoyancy. This level of detrainment fell through the depth of fluid to the base of the tank, after which the flow once more followed that described for regime I.

The two flows described above represent the extremes of the experimentally observed flows - most of the experiments lay between these two cases (represented by IIA and IIH as the most extreme examples). One intermediate experiment was performed in a tank of half the length (achieved by placing the cooling plate midway along the length of the tank and separating the tank into two regions). The smaller volume of fluid evolved faster, and evidence of the more rapid cooling was observed in the formation of long $(5 \mathrm{~mm})$, narrow $(<1 \mathrm{~mm}) \mathrm{Na}_{2} \mathrm{SO}_{4}$ crystals within the fluid in a region up to $5 \mathrm{~cm}$ from the solid surface. These crystals slowly settled to the base of the tank where they built up a loose crystal pile $5 \mathrm{~cm}$ wide and up to $5 \mathrm{~cm}$ in depth. Continued solidification at the cooling plate slowly incorporated this crystal pile into the main solid.

\subsection{Experimental results}

As described above, the roughness of the crystal surface had a large effect on the thermal and compositional evolution of the ambient fluid. When the solid surface was rough, the flux of cold fluid in the mixed upflow established an unstable thermal gradient in the interior, while the flow from a smooth surface produced a stable thermal gradient (figure 14). The increase in the flux of compositionally light fluid arriving at the fluid surface when the solid interface was rough resulted in a stronger density gradient. The strength of the compositional stratification is measured by an average density gradient:

$$
\Delta \rho=\left(\rho_{\text {base }}-\rho_{\text {top }}\right) / \rho_{o},
$$

which is plotted against time for experiments IIA-IIE in figure 15. The plot quite clearly shows the stronger stratification and more rapid evolution in those experiments with a rough crystal surface.

Each experiment began with the convective flux of cold fluid in the thermal boundary layer establishing a thermal gradient in the interior, although the duration of this period depended on the initial structure of the crystallizing solid. The degree to which this filling-box process was affected by the release of light fluid is quantified in figure 16 by plotting the position of the $\theta_{i}=0.3$ isotherm against the dimensionless time $\tau=v G r_{T}^{1 / 4} t /(L H)$, together with the theoretical result for a pure thermal boundary layer (see $\S 5.3$ ). These results confirm the previous qualitative observations that when the solid surface is smooth, the flow of the thermal boundary layer is affected only slightly by the presence of the compositional boundary layer. However, for the experiments in which the crystal surface was initially rough, the filling-box process proceeded up to $60 \%$ faster than the theoretical prediction, due to the increased flux in the turbulent mixed layer. The experimental and theoretical results can be forced to coincide by replacing $v$ with an effective viscosity, which increases with surface roughness. 

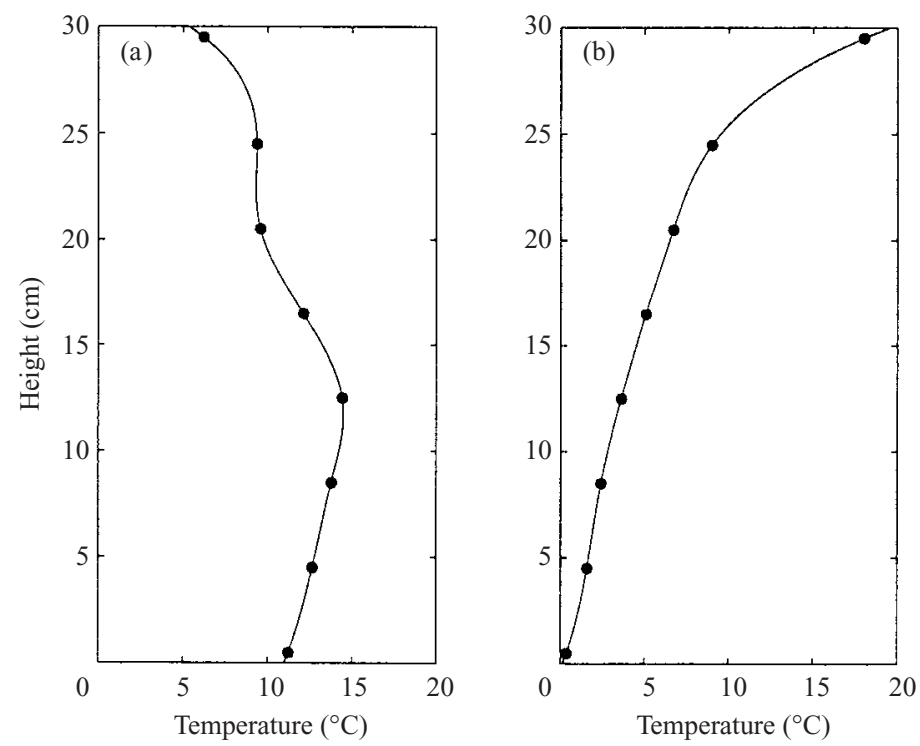

Figure 14. Comparison of the vertical temperature profiles between an experiment with $(a)$ a rough surface (IIH) and (b) a smooth surface (IIA). The profiles were both measured at $\tau=5$.

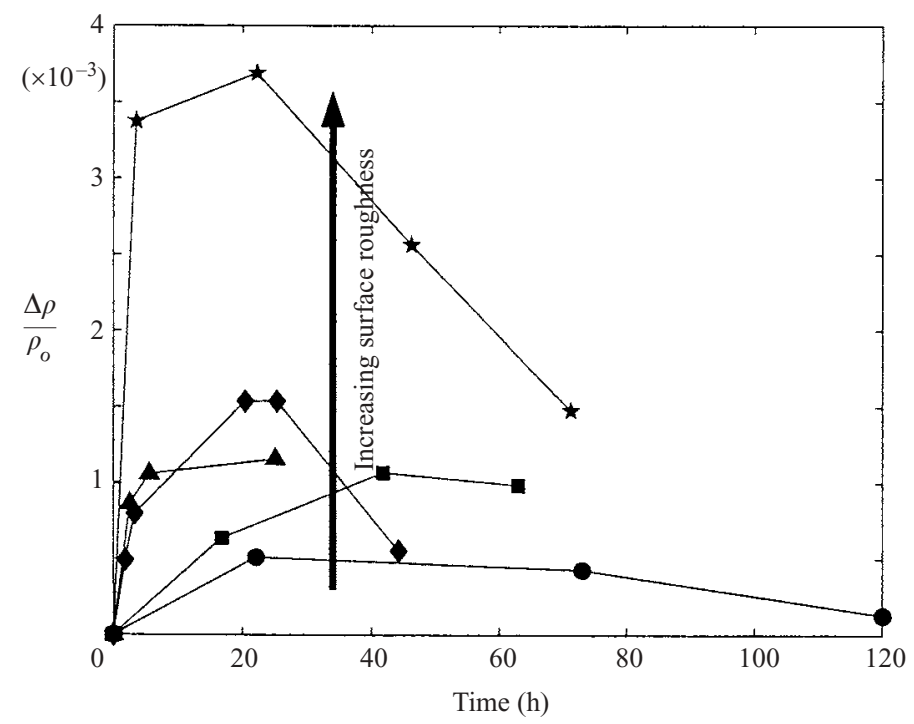

FIGURE 15. Comparison of the strength of the ambient concentration profiles for experiments

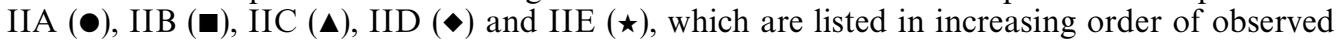
crystal surface roughness.

All of the previous results further confirm the importance of the crystal morphology in the evolution of the ternary system, and consequently, a useful measure of the effect of surface roughness is sought. In a previous analysis of mushy layers, Worster (1991) introduced a parameter, $\mathscr{C}$, which was shown to be important in determining the structure of the solid. In this investigation, $\mathscr{C}=\left(C_{s o l}-C_{o}\right) /\left(C_{o}-C_{c}\right)$ is based 


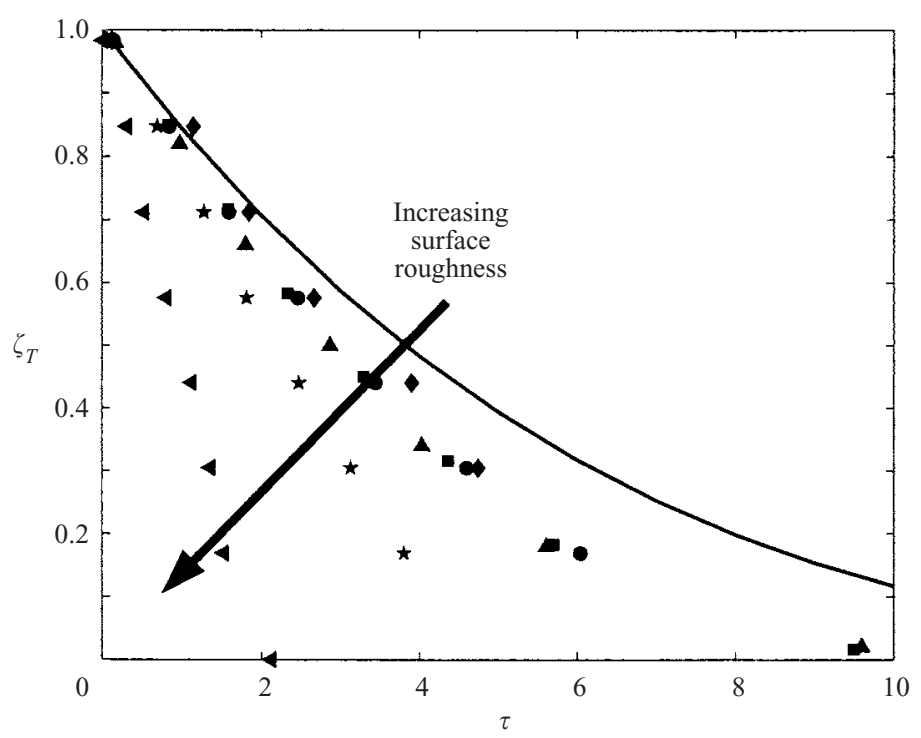

FiguRE 16. The dimensionless height of a standard isotherm plotted against dimensionless time along with the theoretical predictions. Symbols correspond to experiments IIA (๑), IIB

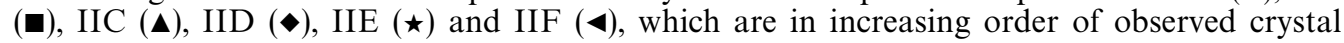
roughness.

on $\mathrm{Na}_{2} \mathrm{SO}_{4}$ concentrations (because the $\mathrm{CuSO}_{4}$ concentrations are approximately constant along the tie lines). The composition of the hydrated solid is $C_{\text {sol }}=44.1$, $C_{o}$ is the composition of the initial fluid and $C_{c}$ is the $\mathrm{Na}_{2} \mathrm{SO}_{4}$ composition at the point where the tie line meets the cotectic. Small values of $\mathscr{C}$ correspond to fluid that initially has high concentrations that are much greater than $C_{c}$, and is hence closer to being saturated in the crystallizing phase $\left(\mathrm{Na}_{2} \mathrm{SO}_{4}\right)$ at the initial temperature. Larger values of $\mathscr{C}$ correspond to fluids with lower initial compositions of $\mathrm{Na}_{2} \mathrm{SO}_{4}$ which are therefore close to the cotectic. Calculated values of $\mathscr{C}$ for these experiments varied systematically from large values $(\mathscr{C}=37)$ for a smooth, closely packed solid, to small values $(\mathscr{C}=5)$ for a rough, more porous solid. One possible explanation for the effect of $\mathscr{C}$ on the crystal morphology is that the fluids that are initially closer to saturation experience greater supercooling within the thermal boundary layer, leading to rapid nucleation and growth of dendritic $\mathrm{Na}_{2} \mathrm{SO}_{4} \cdot 10 \mathrm{H}_{2} \mathrm{O}$ crystals. Fluids that are initially further from saturation experience less supercooling and take longer to form a more closely packed solid. Similar qualitative observations of crystallizing $\mathrm{Na}_{2} \mathrm{SO}_{4} \cdot 10 \mathrm{H}_{2} \mathrm{O}$ were made by Kerr (1985).

The effect of surface roughness on the rate of evolution of the interior fluid can be quantified by measuring the Nusselt and Sherwood numbers, where $N u=(H / \Delta T) \partial T / \partial y$ is the ratio between the measured heat flux and the heat flux that would arise due to conduction only, and $S h$ is the compositional equivalent. To calculate a value of $N u$ from the experimental measurements, the approximation derived by Leitch (1989) for the evolution of the average ambient temperature, $\bar{T}$, at early times is used:

$$
\bar{T}-T_{s}=\left(\bar{T}_{o}-T_{s}\right) \mathrm{e}^{-\kappa N u t / L H},
$$

where $T_{s}$ is a constant surface temperature. Using values of $\bar{T}$ calculated as an average 


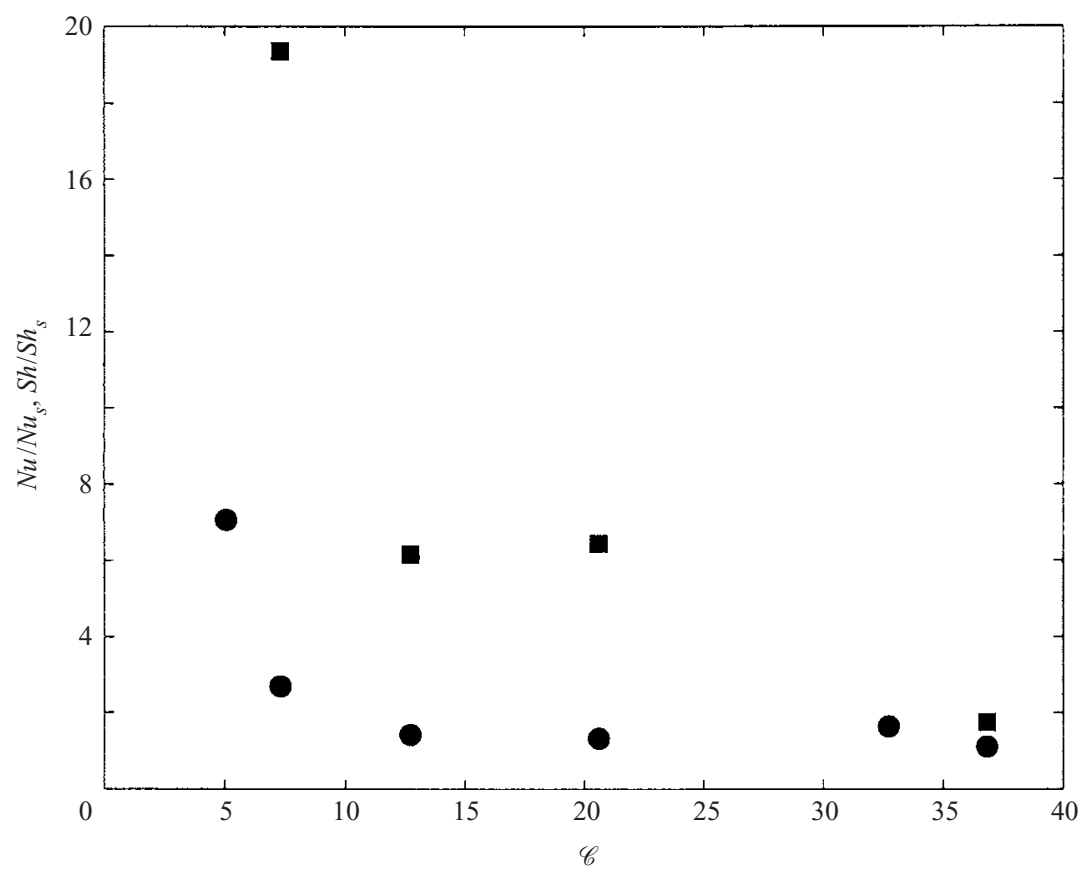

Figure 17. Variation of measured Nusselt $(\bullet)$ and Sherwood (घ) numbers with surface roughness, as measured by $\mathscr{C}$, clearly showing the increase in thermal and compositional fluxes from the theoretical values for flow against a smooth wall.

of the vertical temperature profile and $T_{s}(t=0)$, we found that logarithmic plots of $\left(\bar{T}-T_{s}\right) /\left(T_{o}-T_{s}\right)$ against $t$ were generally linear for the first $1-2$ hours, and the slopes of this section of the graphs were used to calculate $N u$. Values for $S h$ were calculated in a similar manner, although the less frequent compositional measurements resulted in less certainty in the final value. The values of $N u$ (and $S h$ ) obtained for each experiment were compared with the predicted value for a thermal (or compositional) boundary layer only on a smooth wall: $N u_{s}=0.67 \mathrm{Pr}^{1 / 4} \mathrm{Gr}_{T}^{1 / 4}, S h_{s}=0.67 S c^{1 / 4} \mathrm{Gr}_{C}^{1 / 4}$ (Leitch 1989). The results from these experiments are shown in figure 17, showing a definite trend in which the fluxes increase significantly with increasing surface roughness (cf. Leitch 1987 who observed no such trend when using different aqueous solutions at a fixed $\mathscr{C}$ in which the different chemicals were responsible for the variations in surface roughness).

In order to investigate how the competition between the compositional and thermal buoyancies in the boundary layers and the effects of surface roughness combine, the thermistor, concentration and refractive index measurements (as measured from samples on a hand-held refractometer) from each experiment were analysed in detail for evidence of the different boundary layer flows. During the period of unidirectional downflow at the start of each experiment, the thermistors measured a stable thermal gradient at all depths. The end of this period of downflow and the onset of counterflow was identified by a decrease in the refractive index and a slight drop in the temperature of the fluid at the top of the tank, while the temperature at the base continued to decrease. In several experiments, it was also possible to observe directly the onset of counterflow on the shadowgraph. The formation of a mixed upflow was clearly 


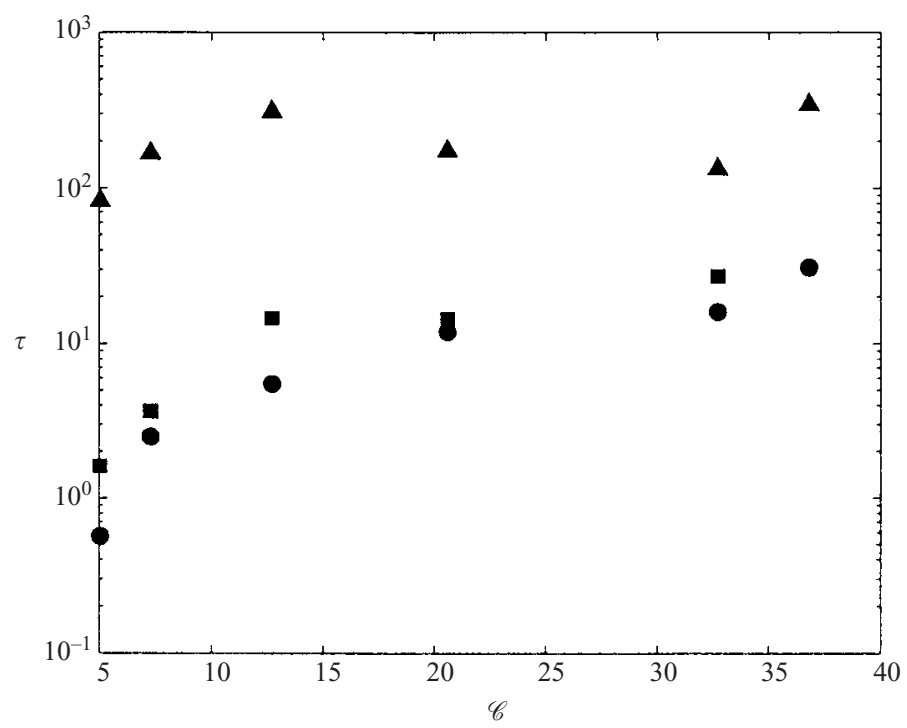

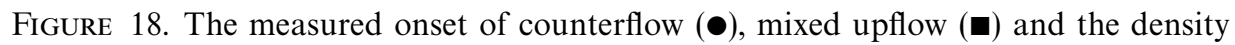
reversal in the compositional boundary layer $(\mathbf{\Lambda})$ as a function of $\mathscr{C}$.

evident in the thermistor measurements as a rapid drop in the temperature at the top of the tank at the same time as the temperature at the base began to increase slightly. Evidence for the reversal of density of the compositional boundary layer was found in the refractive index measurements at the top of the fluid, which became constant with time or increased slightly. This levelling or increase in the refractive index was due to fluid from the top of the tank being entrained into the boundary layers and being transported to the base, and the filling-box process now proceeding to raise the levels of constant density within the ambient fluid. The density reversal was completed when the density at the base began to increase, signifying the arrival of the now dense mixed layer. Figure 18 summarizes all of the information on the onset and duration of the various flows obtained from each of the experiments in terms of the parameter $\mathscr{C}$. The onset and duration of downflow, counterflow or a mixed upflow, as well as the time taken for the fluid composition to reach the binary cotectic, are all strongly affected by the surface roughness (which increases as $\mathscr{C}$ decreases). The onset of the density reversal appears to be almost independent of the surface roughness.

For small values of $\mathscr{C}$, the fluid is initially close to saturation in $\mathrm{Na}_{2} \mathrm{SO}_{4}$ at the initial fluid temperature and the very rough surface would result in an almost immediate mixed upflow. The system continues to evolve rapidly, with the onset of the density reversal dependent on how far the system must evolve to reach the binary cotectic. For large values of $\mathscr{C}$, the fluid is initially close to the binary cotectic, so although the smooth surface results in a slow evolution of the ambient composition, the onset of the density reversal should be almost immediate.

A dimensionless time interval, $\tau_{r}=v G r_{T}^{1 / 4} t_{r} /(L H)$, between the compositionally light boundary layer fluid first arriving at the surface of the fluid and the compositionally dense fluid arriving at the base is plotted against both $\Delta \rho$ (as defined in equation (6.1)) and the time at the onset of the density reversal in figure 19. This parameter $\tau_{r}$ is essentially a measure of how long the reversal of density in 

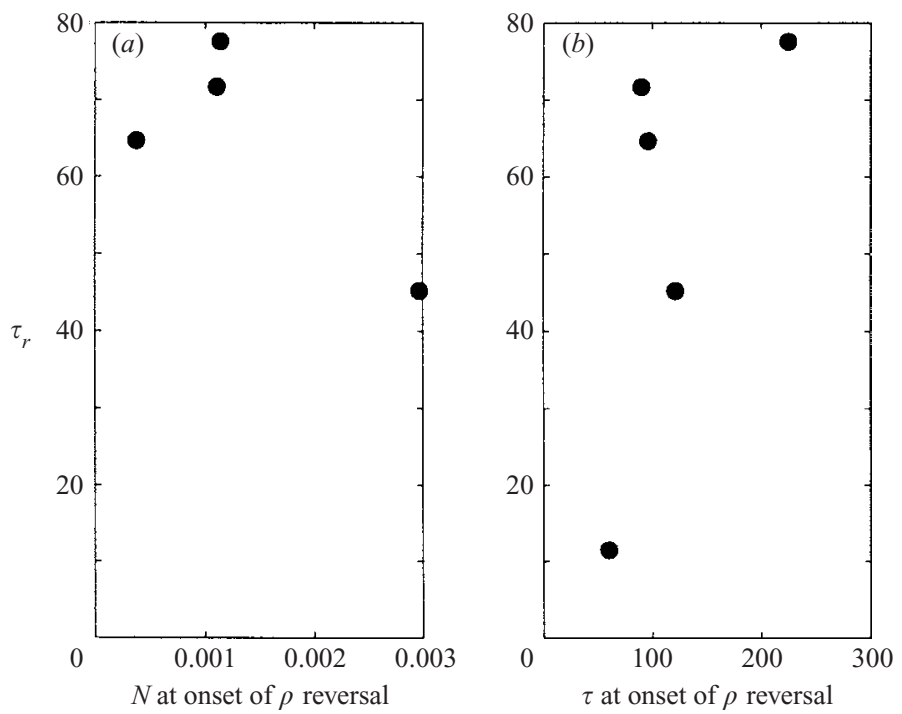

FIGURE 19. The dimensionless time elapsed between the compositional boundary layer arriving at the top of the fluid and arriving at the base, $\tau_{r}=v G r_{T}^{174} t_{r} /(L H)$, plotted against $(a)$ the buoyancy frequency $N$ at the onset of the density reversal and $(b)$ the dimensionless time $v G r_{T}^{1 / 4} t /(L H)$ at the onset of the density reversal.

the compositional boundary layer takes, and hence is expected to be correlated to the difference in density between the ambient fluid at the top and base of the tank. However, figure 19 shows that $\tau_{r}$ does not follow the expected trend of increasing as the density difference between the ambient fluid at the top and base increases. Instead, $\tau_{r}$ is mostly dependent on how quickly the onset of the density reversal is reached, that is on how quickly the system is evolving.

When the surface is smooth, no evidence was found for the intermediate detrainment of one or both boundary layers during the period of density reversal, suggesting that the continued downflow of the outer thermal boundary layer prevents any detrainment of the inner compositional boundary layer. However, when the surface is rough and the density reversal immediately follows a period of mixed upflow, experimental measurements of the position of the coldest fluid in the interior indicate that it changes from being near the surface, through the intermediate depths to the base. It is therefore concluded that in this case, the thermal boundary layer detrains at intermediate depths during the reversal of density. For a rough surface, similar evidence of the detrainment of the compositional boundary layer at intermediate heights is seen when compositional measurements are plotted on ternary diagram: rather than lying directly on the tie line and cotectic, the plotted point sits between the two, suggesting some mixing of fluids with the same densities but different compositions.

\subsection{Theoretical predictions}

The first theoretical investigation to demonstrate the existence of counterflow when the buoyancies in the two boundary layers are opposed was presented by Gebhart \& Pera (1971). More recently, Nilson \& Baer (1982) quantified the conditions that lead to a counterflow $\left(L e^{1 / 3}<\Gamma<L e\right)$, a unidirectional downflow $\left(\Gamma<L e^{1 / 3}\right)$, or a 
unidirectional upflow $(\Gamma>L e)$. The borderlines between these regimes depend on the relative strength of the buoyancy forces $(\Gamma=(\beta \Delta C) /(\alpha \Delta T))$ as well as the ratio of chemical to thermal diffusivities $(L e=\kappa / D)$, which also provides a measure of the relative fluxes in the two boundary layers. However, these relationships were determined for laminar flow against a smooth, vertical wall and hence are not immediately applicable to this investigation. In the extreme case of boundary layer flow completely within a porous medium, Lowell (1985) presented the equations for two-component boundary layers with opposing buoyancies, and discussed qualitatively when the different flow regimes arise. In the experiments presented here, the conditions range from a smooth surface to a surface that is sufficiently rough that the inner compositional boundary layer, at least, behaves as if it is within a porous medium. Consequently, it is expected that the observed flows lie somewhere between the predictions of Nilson \& Baer (1982) and Lowell (1985).

In order to quantify the effect of surface roughness on the different boundary layer flows, we begin by comparing the predictions of Nilson \& Baer (1982) for a smooth surface with the results from the experiments reported here. The variations in $\Gamma$ as crystallization proceeds are calculated from

$$
\Gamma=\frac{\beta\left(C_{s}-C_{\infty}\right)}{\alpha\left(T_{s}-T_{\infty}\right)} .
$$

The interior composition, $C_{\infty}$, was found as an average from the compositional profiles, while the composition at the surface of the solid, $C_{w}$, was assumed to be the most fractionated fluid in the interior. The ambient temperature, $T_{\infty}$, was found from averaging the thermistor measurements, while the temperature at the crystal surface, $T_{s}$, was calculated from the ternary phase diagram assuming that the concentration at the surface was on the liquidus. Concentration and temperature data from experiments IIA-IIC and IIE were used to plot the time evolution of $\Gamma$, from which the values of $\Gamma$ at the observed onset of counterflow $\left(\Gamma_{c}\right)$ and upflow $\left(\Gamma_{u}\right)$ were interpolated. Figure 20 summarizes the relationship between the surface roughness, as measured by $\mathscr{C}$, and the calculated values of $\Gamma_{c}$ and $\Gamma_{u}$. All of these show an onset of counterflow at $\Gamma \gtrsim 1-$ much lower than the value of $\Gamma=7.75$ calculated from $\Gamma=L e^{1 / 3}$ (Nilson $\&$ Baer 1982). In addition, that theory predicts that unidirectional upflow should not occur during any of these experiments $(\Gamma=467)$, which clearly is not the case. The effect of surface roughness therefore leads to much earlier onset of counterflow and/or upflow.

In the extreme case of double-diffusive boundary layer flow entirely within a porous medium, Lowell (1985) argued that a simpler viscous stress relation and the lack of a no-slip boundary condition at the wall lead to different criteria for upflow, counterflow and downflow than those predicted by Nilson \& Baer (1982). Although no explicit expressions for $\Gamma_{c}$ and $\Gamma_{u}$ were presented, analysis of the equations presented by Lowell (1985) suggest a value of $\Gamma_{c}=1$ ( $\Gamma_{u}$ could not be predicted analytically from the presented equations). This value is much closer to our experimentally measured value than the predication of Nilson \& Baer (1982). The arguments that were employed for boundary layers in porous media possibly also apply to this investigation, where the boundary conditions are defined at the contact between spiky crystals and the liquid, and hence probably lie somewhere between those for a flat wall and for a completely porous media.

A further possible explanation for the significant differences between theory and experiment lies in the effect of surface roughness on the fluxes in the boundary layers. In the experiments, any degree of surface roughness increases the flux in the 


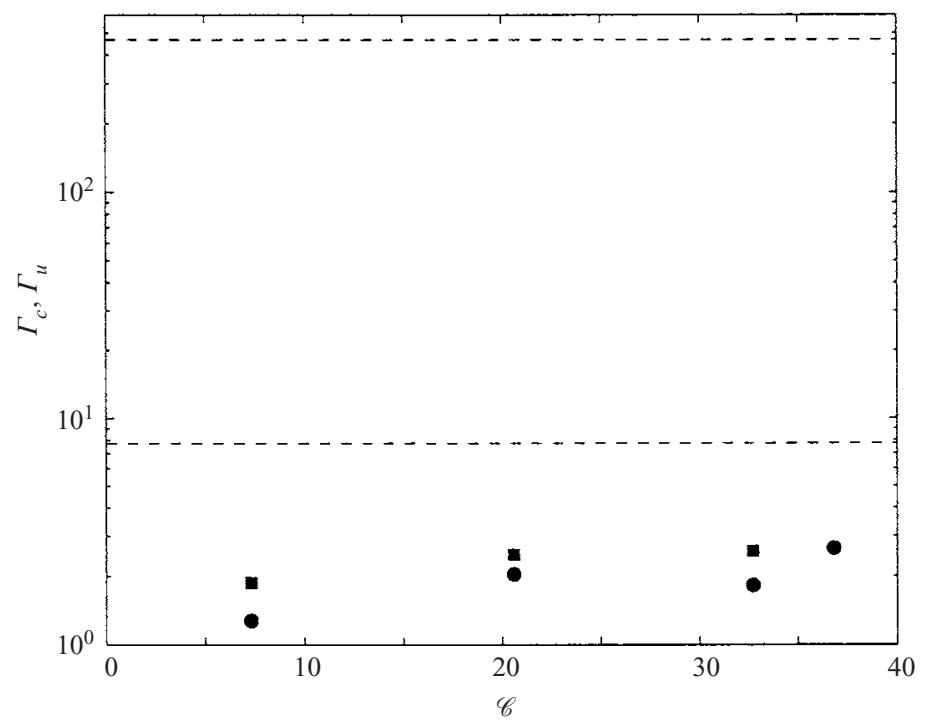

FIgURE 20. The experimentally measured values of $\Gamma$ at the onset of counterflow ( $\bullet$ ) and upflow (ם), plotted as a function of $\mathscr{C}$ as a measure of surface roughness. The theoretical results (dashed lines) of Nilson (1982) for the flow against a flat plate $(\mathscr{C} \rightarrow \infty)$ are at $\Gamma_{c}=7.75$ and $\Gamma_{u}=467$.

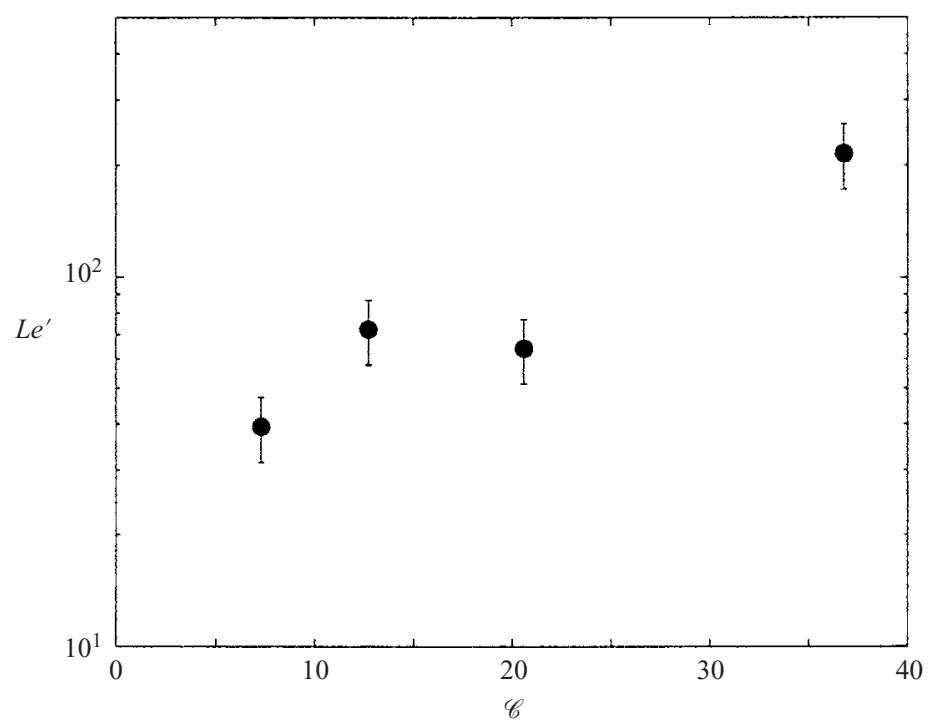

FiguRE 21. The experimentally calculated values of the effective Lewis number plotted against $\mathscr{C}$ as a measure of surface roughness.

compositional boundary layer until the fluxes in the two boundary layers become comparable. In terms of the theory, equal fluxes in the boundary layers would also result if $\kappa$ and $D$ were equal and $L e=1$. Increasing surface roughness therefore can be quantified as a decreasing effective Lewis number, from which $\Gamma_{c}$ and $\Gamma_{u}$ as calculated from the predictions of Nilson \& Baer (1982) also decrease. An effective 
Lewis number is defined as

$$
L e^{\prime}=\frac{\kappa^{\prime}}{D^{\prime}}=L e^{5 / 4} \Gamma^{1 / 4} \frac{N u}{S h},
$$

with $\kappa^{\prime}=\kappa N u / N u_{s}, D^{\prime}=D S h / S h_{s}, N u_{s}$ and $S h_{s}$ as defined previously, and with $N u$ and $S h$ determined experimentally. A plot of the calculated effective Lewis number against $\mathscr{C}$ is shown in figure 21, confirming the expected general decrease in $L e^{\prime}$ as the surface roughness increases. Qualitatively, therefore, the use of an effective Lewis number predicts the general trends observed experimentally, although quantitatively, $L e^{\prime}$ is still an order of magnitude greater than what would be expected to produce the observed experimental behaviour.

From the results shown in both figures 20 and 21, the deviation from the theory of Nilson \& Baer (1982) occurs rapidly with any degree of surface roughness. Further measurements would be needed, both in this system and others, to quantify this behaviour, but it remains clear that for a surface that is not completely smooth, an effective Lewis number rapidly decreases from the predictions of Nilson \& Baer (1982) to approach unity. For any degree of surface roughness, therefore, counterflow and upflow are likely to arise at values of $\Gamma \gtrsim 1$.

\section{Conclusions}

A detailed experimental study of the dynamics of a ternary system undergoing solidification from the side has been presented. This work has significantly expanded on previous investigations into the lateral solidification of binary and ternary systems. Three major regimes of behaviour were identified, and the flow in two of these was studied in detail.

When the driving buoyancies of the thermal and compositional boundary layers act in the same direction (the fluid released on crystallization is dense), it was shown that the early thermal evolution of the interior fluid is almost unchanged from that predicted for thermal convection only, that is, the compositional boundary layer has little effect. Only at later times do differences arise, as the much slower growth of the compositionally stratified region results in the thermal boundary layer detraining at the top of the compositional gradient. This intermediate detrainment effectively separates the interior fluid into two layers with compositional convection limited to the lower layer and thermal convection mostly in the upper layer. Within the compositional stratification several double-diffusive layers eventually developed, with the ambient temperature a local minimum at the base of each of these layers. These local temperature minima correlated with the faster growth of the solid, resulting in a scalloped profile in the solid ice. While the surface of the ice remained smooth, the porosity of the solid decreased from over $20 \%$ near the plate where the growth was fastest, to virtually $0 \%$ at the solid surface and at shallow depths, where the solid grew extremely slowly.

The second identified regime was shown to exhibit a wide range of dynamics due to both the opposed buoyancies in the boundary layers and the effects of surface roughness. It was found that the roughness of the growing solid was dependent on $\mathscr{C}$, which is a measure of the concentration of the crystallizing component in the initial fluid. Each experiment began with a unidirectional downflow in the boundary layers. Then, depending on the surface roughness, either a counterflow, an upflow, or in some cases, both were subsequently observed. When the composition of the fluid reached the cotectic, the density of the compositional boundary layer started to increase and 
eventually both boundary layers fell to the base of the fluid region. Qualitatively, the dynamics of the boundary layers varied systematically with the roughness of the solid surface, which was quantified in terms of an experimentally determined effective Lewis number. The effect of the surface roughness on the boundary layer flows was then combined with the predictions from previous theories for flow against a smooth vertical wall to qualitatively illustrate the effects of increasing surface roughness on the boundary layer dynamics.

We thank Mark Hallworth for his assistance with the experiments, Mervyn Greaves for his help with the atomic absorption measurements and Ross Kerr and Grae Worster for their helpful comments on earlier drafts. We also thank the anonymous referees for their many helpful comments and suggestions.

\section{REFERENCES}

Aitta, A., Huppert, H. E. \& Worster, M. G. 2001 Diffusion-controlled solidification of a ternary melt from a cooled boundary. J. Fluid Mech. 432, 201-217.

BAINES, W. D. \& TuRner, J. S. 1969 Turbulent buoyant convection from a source in a confined region. J. Fluid Mech. 37, 51-80.

Chen, C.-F. \& Turner, J. S. 1980 Crystallization in a double-diffusive system. J. Geophys. Res. 85, 2573-2593.

Gebhart, B. \& Pera, L. 1971 The nature of vertical natural convection flows resulting from the combined buoyancy effects of thermal and mass diffusion. Intl J. Heat Mass Transfer 14, 2025-2050.

Huppert, H. E. 1990 The fluid mechanics of solidification. J. Fluid Mech. 212, 209-240.

Huppert, H. E., Kerr, R. C. \& Hallworth, M. A. 1984 Heating or cooling a stable compositional gradient from the side. Intl J. Heat Mass Transfer 27, 1395-1404.

Huppert, H. E. \& Sparks, R. S. J. 1984 Double-diffusive convection due to crystallization in magmas. Anuu. Rev. Earth Planet. Sci. 12, 11-37.

Huppert, H. E. \& Turner, J. S. 1978 On melting icebergs. Nature 271, 46-48.

HupPert, H. E. \& TuRner, J. S. 1980 Ice blocks melting into a salinity gradient. J. Fluid Mech. 100, $367-384$.

Huppert, H. E. \& Worster, M. G. 1985 Dynamic solidification of a binary melt. Nature 314, 703-707.

HurLe, D. T. J. 1993 Handbook of Crystal Growth, vol. 1-3. North-Holland.

JARVIS, R. A. \& Huppert, H. E. 1995 Solidification of a binary alloy of variable viscosity from a vertical boundary. J. Fluid Mech. 303, 103-132.

KERR, R. C. 1985 Crystallization and compositional convection in geological fluid mechanics. PhD Thesis, Cambridge University.

KerR, R. C. \& TAIT, S. R. 1986 Crystallization and compositional convection in a porous medium with application to layered igneous intrusions. J. Geophys. Res. 91, 3591-3608.

KerR, R. C. \& Turner, J. S. 1982 Layered convection and crystal layers in multicomponent systems. Nature 298, 731-733.

Kurz, W. \& Fisher, D. J. 1986 Fundamentals of Solidification. Trans. Tech. Publications.

LeITCH, A. M. 1987 Various aqueous solutions crystallizing from the side. In Structure and Dynamics of Partially Solidified Systems. (ed. D. E. Loper) Martinus Nijhoff.

Leitch, A. M. 1989 Evolution of a binary system crystallizing in a confined region. Intl J. Heat Mass Transfer 32, 2087-2098.

LOWELL, R. P. 1985 Double-diffusive convection in prtially molten silicate systems: its role durig magma production and in magma chambers. J. Volcanol. Geotherm. Res. 26, 1-24.

McBirney, A. R. 1980 Mixing and unmixing of magmas. J. Volcanol. Geotherm. Res. 7, 357-371.

NiLSON, R. H. 1985 Countercurrent convection in a double-diffusive boundary layer. J. Fluid Mech. 160, 181-210.

Nilson, R. H. \& BAER, M. R. 1982 Double diffusive counterbuoyant boundary layer in laminar natural convection. Intl J. Heat Mass Transfer 25, 285-287. 
Press, W. H., Flannery, B. P., Teukolsky, S. A. \& Vetterling, W. T. 1992 Numerical Recipes in C: The Art of Scientific Computing. Cambridge University Press.

Thompson, M. E. \& Szekely, J. 1987 Double diffusive convection during solidification at a vertical wall. In Structure and Dynamics of Partially Solidified Systems. Martinus Nijhoff.

Turner, J. S. 1979 Buoyancy Effects in Fluids. Cambridge University Press.

TURNER, J. S. 1980 A fluid-dynamical model of differentiation and layering in magma chambers. Nature 285, 213-215.

TuRner, J. S. \& Gustafson, L. B. 1981 Fluid motions and compositional gradients produced by crystallization or melting at vertical boundaries. J. Volcanol. Geotherm. Res. 11, 93-125.

Washburn, E. E. (Ed.) 1928 International Critical Tables of Numerical data, Physics, Chemistry and Technology. McGraw-Hill.

West, D. R. F. 1982 Ternary Equilibrium Diagram, 2nd Edn. Chapman and Hall.

Worster, M. G. 1991 Natural convection in a mushy layer. J. Fluid Mech. 224, 335-359.

Worster, M. G. \& Leitch, A. M. 1985 Laminar free convection in confined regions. J. Fluid Mech. 156, 301-319. 